\title{
Electrospinning of ceramic nanofibers: Fabrication, assembly and applications
}

\author{
Hui WU, Wei PAN*, Dandan LIN, Heping LI \\ State Key Lab of New Ceramic and Fine Processing, Department of Materials Science and Engineering, \\ Tsinghua University, Beijing 100084, China
}

Received March 1, 2012; Accepted March 5, 2012

(C) The Author(s) 2012. This article is published with open access at Springerlink.com

\begin{abstract}
This paper provides a brief review of current research activities that focus on the synthesis and controlled assembly of inorganic nanofibers by electrospinning, their electrical, optical and magnetic properties, as well as their applications in various areas including sensors, catalysts, batteries, filters and separators. We begin with a brief introduction to electrospinning technology and a brief method to produce ceramic nanofibers from electrospinning. We then discuss approaches to the controlled assembly and patterning of electrospun ceramic nanofibers. We continue with a highlight of some recent applications enabled by electrospun ceramic nanofibers, with a focus on the physical properties of functional ceramic nanofibers as well as their applications in energy and environmental technologies. In the end, we conclude this review with some perspectives on the future directions and implications for this new class of functional nanomaterials. It is expected that this review paper can help the readers quickly become acquainted with the basic principles and particularly the experimental procedure for preparing and assembly of $1 \mathrm{D}$ ceramic nanofiber and its arrays.
\end{abstract}

Key words: electrospinning; nanofibers; functional ceramics; catalyst

\section{Introduction}

One-dimensional (1D) nanostructures such as nanowires, nanotubes, nanoribbons and nanofibers are continuing to be at the forefront of nanoscience and nanotechnology [1-8]. In particular, ceramic with 1D nano-architectures received increasing interest since it provides a good material system to investigate the dependence of electrical, optical, thermal and mechanical properties on dimensionality and size

\footnotetext{
* Corresponding author.

E-mail: panw@tsinghua.edu.cn
}

reduction [9-14]. 1D ceramic nanomaterials with their large surface-to-volume ratio have the potential for use in various applications where high porosity is desirable [11-13]. For example, inorganic nanowires are expected to play an important role as promising building blocks for nanoscale electronic $[9,10,15]$, optoelectronic $[15,16]$ and sensor device $[12,17,18]$. Most recently, ceramic nanowires have been explored as effective electrode materials for electrochemical energy storage devices $[19,20]$. In the past two decades, worldwide efforts in both the theory and the experimental investigation of growth, characterization and applications of 1D inorganic nanostructures have resulted in a mature, multidisciplinary field. For practical application of $1 \mathrm{D}$ ceramic nanomaterials, 
scalable materials production and convenient devices integration are extremely important. Technological advances over have resulted in the realization of several competing processes for fabricating nanometer-size ceramic materials. So far, many kinds of 1D ceramic nanomaterials have been successfully synthesized by a rich variety of methods, and the detailed research information on these 1D nanostructures can be readily seen in the pertinent literature [10,15,18,21-23].

Among various chemical or physical synthetic approaches, electrospinning appears to be the most straightforward and versatile technique for generating 1D nanostructures [24-26]. Electrospinning was first patented in the US in 1902; however, the process was largely forgotten until the 1990s [27,28]. Electrospinning is currently the only technique that allows the fabrication of continuous fibers with diameters down to a few nanometers. Fibers with complex architectures, such as core-shell fibers or hollow fibers, can be produced by special electrospinning methods [24-26]. It is also possible to produce structures ranging from single fibers to ordered arrangements of fibers. Electrospinning is not only employed in university laboratories, but is also increasingly being applied in industry. The scope of applications, in fields as diverse as optoelectronics, sensor technology, catalysis, filtration, and medicine, is very broad $[27,29,30]$. However, electrospinning has been largely limited to the fabrication of nanofibers of organic polymers materials, including synthetic and natural polymers, polymer alloys, and polymers loaded with chromophores, nanoparticles, or active agents, as it is relatively convenient to prepare a polymer solution or melt with appropriate rheological properties required for electrospinning [27,29,30]. Metals and ceramics are usually considered to be not directly spinnable [27,31] . Recent efforts by several research groups have made it possible to generate ceramic nanofibers using electrospinning technique [24,28-30, 32-35]. This review will present a brief overview of recent progress in this research area, with a focus on the work carried out in our group [16,35-58]. After briefly introducing the basic principles of electrospinning, this paper will review the general experimental procedures for the preparation of electrospinning ceramic nanofibers, and will highlight several unique features associated with the technique and illustrate the potential of electrospinning in future research related to ceramic processing. We will also discuss the controlled assembly and patterning of electrospun ceramic nanofibers. Finally, we will highlight some recent achievements on the study of physical properties of electrospun ceramic nanofibers and their practical applications in the context of nanoelectronics, catalysis, environmental science, and energy technology [16,35-56]. By the end, we also provide some personal perspectives on the future development of this technique. It is expected that this review paper can help the readers quickly become acquainted with the basic principles and particularly the experimental procedure for preparing and assembly of $1 \mathrm{D}$ ceramic nanofiber and its arrays.

\section{Principle of electrospinning}

Electrospinning is based on inducing static electrical charges on the molecules of a solution at such a density that the self-repulsion of the charges causes the liquid to stretch into a fiber in an electric field [27]. Provided there is no breakage in the stretched solution, a single strand of continuous fiber is formed upon solvent evaporation. When a high voltage is applied to the solution, the ohmic current distributes the charges throughout the molecules [27]. As the solution is ejected from the spinneret tip, the ohmic current transits to a predominantly convective current. The charges are transported from the electrospinning tip to the target through the deposition of the fiber. The current stops oscillating when the deposition becomes stable [29]. This can be used to monitor the spinning process. The electrical charges used for electrospinning can be positive, negative or both (alternating current). Although most reported electrospinning experiments were carried out using a positive potential, it has been shown that a negative potential produces nanofibers with a narrower diameter distribution $[59,60]$. This was explained by the fact that electrons can be dispersed more rapidly and uniformly than the much heavier protons.

In a typical electrospinning setup, a high-voltage source is connected to a metallic needle, which is attached to a solution reservoir (Fig. 1). The needle has a relatively small orifice that concentrates the electric charge density on a small pendant drop of solution. Although a metallic spinneret such as a needle is convenient for the application of charge to the solution, the process also works if a high voltage is applied to the solution using a dedicated electrode with a 


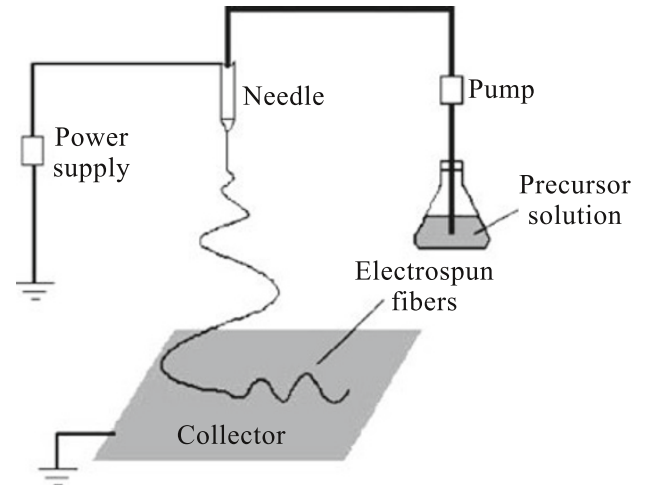

Fig. 1 Schematic drawing of the electrospinning apparatus. Reprinted with permission from $\mathrm{Wu} \mathrm{H}$, Pan W, J. Am. Ceram. Soc. 2006; 89: 699-701. Copyright 2005 The American Ceramic Society

nonconducting spinneret. A porous cylinder has also been used for electrospinning, and it is possible to induce charges on a free solution droplet without direct contact to form a fiber. The theoretical modeling of a viscous leaky dielectric solution subjected to a critical voltage showed that it becomes unstable in an electric field when the surface tension can no longer maintain its static equilibrium [27,31,59]. At this voltage, protrusions form on the solution surface and jets of solution are ejected. Any perturbation or nonuniformity on the solution surface will concentrate charges in regions with higher curvature. If the curvature is sufficiently large for the potential difference between such a region and the collector to reach a critical value, the solution erupts from the surface and accelerates towards the collector. This has given rise to numerous designs in which drums, spikes, ridges and disks have been used to dispense the solution for electrospinning. The diameter and morphology of electrospun nanofibers can be controlled by adjusting the following parameters during electrospinning [27,31,59]:

1. Molecular weight, molecular-weight distribution and architecture (branched, linear etc.) of the polymer;

2. Solution properties (viscosity, conductivity and surface tension);

3. Electric potential, flow rate and concentration;

4. Distance between the capillary and collection screen;

5. Ambient parameters (temperature, humidity and air velocity in the chamber);

6. Motion of target screen (collector);
7. Needle gauge.

\section{Electrospinning of ceramic nanofibers}

Electrospinning technique has been recognized as a fabrication method for polymer and carbon nanofibers [59]. Since 2002, electrospinning has been further explored as a high efficiency method for the generation of $1 \mathrm{D}$ ceramic nanofibers [26,29,32]. In the past decade, various ceramic nanofibers are fabricated by the combination of two conventional techniques: electrospinning and sol-gel [32,34]. Generally, ceramic nanofibers are made by the electrospinning of ceramic precursors in the presence of polymer followed by calcination at higher temperatures. In order to generate well-controlled and high-quality ceramic nanofibers by electrospinning, one typically process has to use the following procedure:

(1) Preparation of an electrospinning solution containing a polymer and sol-gel precursor to the ceramic material,

(2) Electrospinning of the solution under appropriate conditions, generate precursor nanofibers containing inorganic precursor and polymer assistant materials.

(3) Calcination of the precursor nanofibers at high temperature to remove polymers and obtain the ceramic phase.

Various oxide nanofibers can be synthesized by this approach. Notable examples includes $\mathrm{ZnO}, \mathrm{CuO}, \mathrm{NiO}$, $\mathrm{TiO}_{2}, \mathrm{SiO}_{2}, \mathrm{Co}_{3} \mathrm{O}_{4}, \mathrm{Al}_{2} \mathrm{O}_{3}, \mathrm{SnO}_{2}, \mathrm{Fe}_{2} \mathrm{O}_{3}, \mathrm{LiCoO}_{2}$, $\mathrm{BaTiO}_{3}, \mathrm{LaMnO}_{3}, \mathrm{NiFe}_{2} \mathrm{O}_{4}$ and $\mathrm{LiFePO}_{4}$ [16,26,27,29, $30,35,45,46,51-54,61-78]$. A typical spinnable precursor solution should contain a salt precursor, a polymer and a relatively volatile solvent such as ethanol, water, isopropanol, chloroform, and dimethylformamide (DMF) [26,59-76]. Poly(vinyl alcohol) (PVA) is one of the most popular polymers employed as a matrix due to its high solubility in water and its good compatibility with many salts, including zinc acetate and copper nitrate [49]. In addition, other polymers, such as poly(vinyl pyrolidone) (PVP), poly(vinyl acetate) (PVAc), poly-acrylonitrile (PAN), poly(methyl methacrylate) (PMMA), and poly(acrylic acid) (PAA) have also been widely used $[26,27,31,35,69]$. 

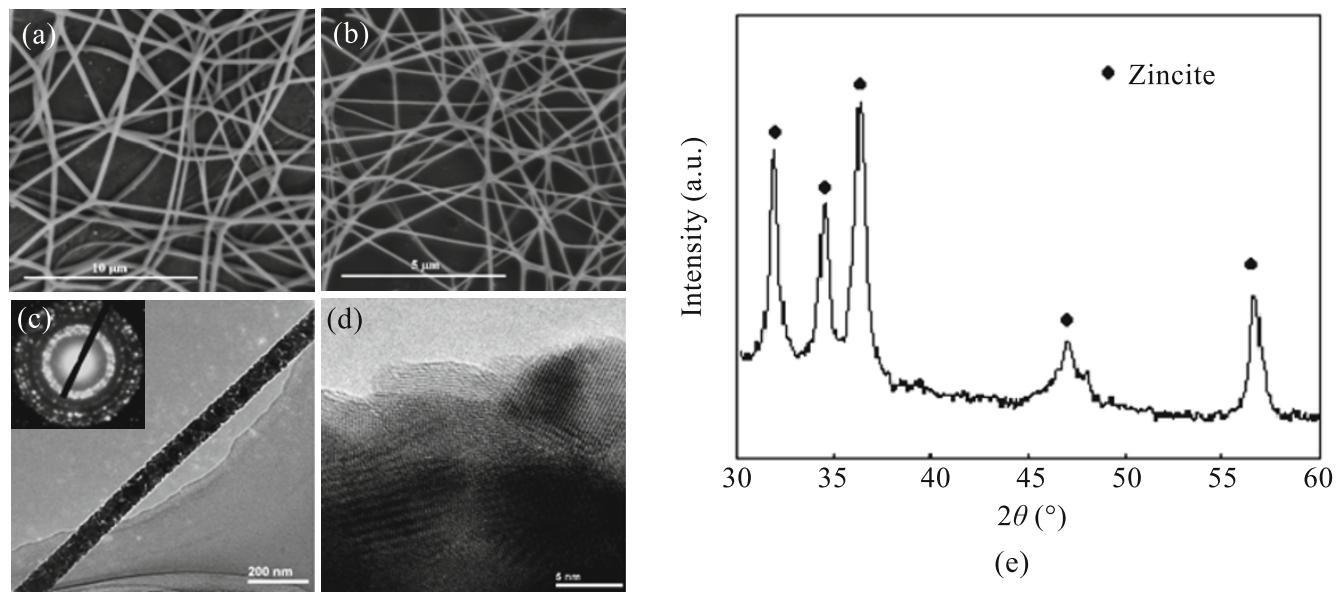

(e)

Fig. 2 (a) Field emission scanning electron microscopy image of the precursor fibers collected in random orientation. The fibers have an average diameter of about $230 \mathrm{~nm}$. (b) $\mathrm{ZnO}$ nanofibers prepared by calcination of the precursor fibers at $500{ }^{\circ} \mathrm{C}$ for $4 \mathrm{~h}$. The fibers remain continuous, with a uniform morphology. The diameter of the $\mathrm{ZnO}$ nanofibers decreased to $70 \mathrm{~nm}$. (c) Transmission electron microscopy (TEM) image of a single $\mathrm{ZnO}$ nanofiber. Inset: the selected area electron diffraction pattern. (d) High-resolution TEM (HRTEM) image of the same sample, indicating the polycrystalline structure of the calcined fiber. (e) X-ray diffraction results for zinc acetate/polyvinyl alcohol precursor fibers' calcination at $500{ }^{\circ} \mathrm{C}$ for $6 \mathrm{~h}$ [43]. Reprinted with permission from Lin D D, Pan W, Wu H, J. Am. Ceram. Soc. 2007; 90: 71-76. Copyright 2006 The American Ceramic Society

One advantage of electrospinning method for ceramic nanofiber processing is the component of nanofibers can be easily controlled by tuning electrospinning precursor solutions, and the fiber morphologies can be adjusted during electrospinning and calcination processes. For example, ultra-thin fibers of zinc oxide can be prepared by sol-gel processing and the electrospinning technique using PVA and zinc acetate as precursors $[36,40,43,47-49,70$, 72]. After electrospinning and calcination of the precursor fibers, ceramic $\mathrm{ZnO}$ nanofibers were fabricated as demonstrated by X-ray diffraction (XRD) $[36,43]$. TEM images of the nanofibers after calcinations indicated that the fibers had a smooth surface, and were formed through the agglomeration of $\mathrm{ZnO}$ nanoparticles with domain sizes of about $10 \mathrm{~nm}$ $[36,43]$. Experimental results show that the diameter of the precursor fibers can be controlled by adjusting the concentration of zinc acetate, and the morphology of the inorganic $\mathrm{ZnO}$ fibers is influenced by calcination time $[36,43]$. One advantage of electrospinning method for ceramic nanofiber processing is the component of nanofibers can be easily controlled by tuning electrospinning precursor solutions, and the fiber morphologies can be adjusted during electrospinning processes [16,39].

Doping or incorporation of foreign materials into a solid ceramic matrix material is often required for many applications such as catalysis and chemical sensors [12]. One remarkable feature that distinguishes the electrospinning approach from other techniques for preparing ceramic nanofibers is that it is very simple and convenient to incorporate or encapsulate other materials into the nanofibers and nanotubes. In an
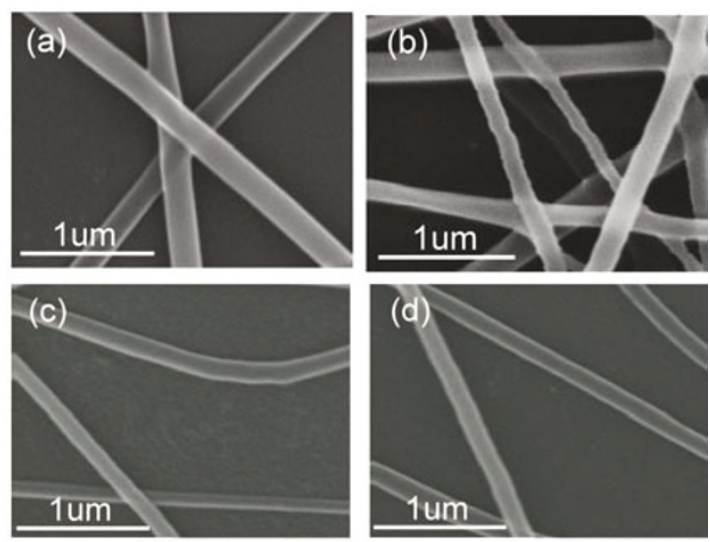

Fig. 3 Scanning electron microscopy images of polyvinyl alcohol (PVA)/zinc acetate composite fibers electrospun at the voltage of $20 \mathrm{kV}$, with various $\mathrm{Al}$ contents (PVA wt $\% 510 \%$ ): $\mathrm{Al}$ at.\%5(a) $0 \%$, (b) $1.0 \%$, (c) $2.0 \%$, (d) $3.0 \%$ in aluminumdoped zinc oxide nanowires [39]. Reprinted with permission from Wu H, Lin D D, Zhang R, Pan W, J. Am. Ceram. Soc. 2008; 91: 656-659. Copyright 2007 The American Ceramic Society 
electrospinning process, functional materials (molecules or nanoparticles) can be easily doped or incorporated into nanofibers by adding these materials or their precursors to the spinning solutions. For example, Lin et al. fabricated aluminum-doped zinc oxide (AZO) nanofibers with precisely controlled $\mathrm{Al}$ dopant concentration by adding aluminum nitrate in electrospinning solutions (Fig. 3) [16,39]. The diameter of AZO nanofibers decreased and became uniform when the concentration of $\mathrm{Al}$ increased from 0 to 3.0 at.\%. The dependence of the morphology and diameter of the electrospun nanofibers on the processing parameters, including PVA concentration, applied voltage, and the Al dopant, was investigated in their research. It was found that the viscosity and conductivity were of most importance to the morphology of the e-spinning fibers, given constant electric field strength and flow rate [16,39]. Another example for this controlled doping is $\mathrm{Ag}-\mathrm{ZnO}$ nanofibers by electrospinning [47,48]. Ag nanoparticles with controlled concentration have been successfully loaded in $\mathrm{ZnO}$ nanofibers by Lin et al. (Fig. 4).

Electrospinning technique can also be used for fabricating nanofibers composed by non-oxide ceramics including carbide, boride, nitride, silicide and sulphide [38,50,79-87]. Wu et al. synthesized nitride nanofibers via electrospinning for the first time [50]. Group III N alloys, particularly GaN, have a huge potential for revolutionary semiconductor device configurations. Extremely long GaN nanofibers on a large scale can be synthesized based on electrospinning. The strategy to obtain GaN nanofibers can be divided into three steps: (1) The electrospinning of precursor

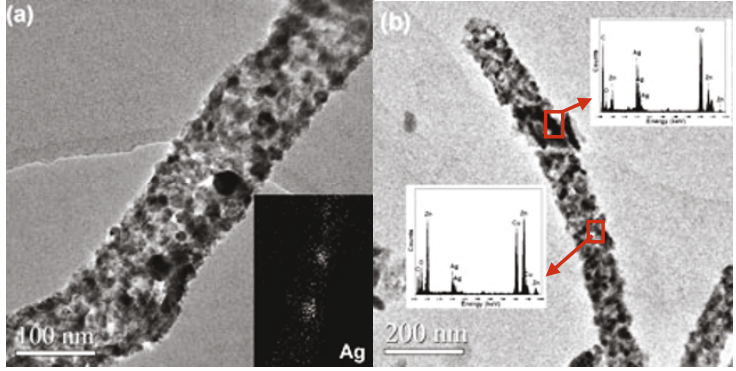

Fig. 4 TEM images of the Ag- $\mathrm{ZnO}$ composite nanowires: (a) 10.0 at. \% Ag. inset: EDX mapping of $\mathrm{Ag}$ element along the nanowire; (b) 15.0 at. $\%$ Ag. Insets: typical EDX microanalysis on selected areas of a single nanowire [47]. Reprinted with permission from Lin D D, Wu H, Zhang R, Pan W, Chem. Mater. 2009; 21: 3479-3484. Copyright 2009 American Chemical Society

composite nanofibers that comprise polymer and gallium nitrate; (2) Calcination of the composite nanofibers in air to thoroughly remove organic components and to form gallium oxide nanofibers; (3) In situ conversion of the as-prepared oxide nanofibers into nitride nanofibers in an ammonia atmosphere at high temperature [50]. SEM image shows that the continuous structure of the initial $\mathrm{Ga}_{2} \mathrm{O}_{3}$ nanofiber was maintained after ammonization. The length of the synthesized GaN nanofibers could reach the centimeter scale, and the average fiber diameter is only $40 \mathrm{~nm}$, which indicates an ultrahigh aspect ratio of the GaN nanofibers (Fig. 5a). TEM images (Fig. 5b) also reveal the fibrillar structure of the ammoniated samples. A selected-area electron-diffraction (SAED) pattern shows that the nanofibers are polycrystalline, and a

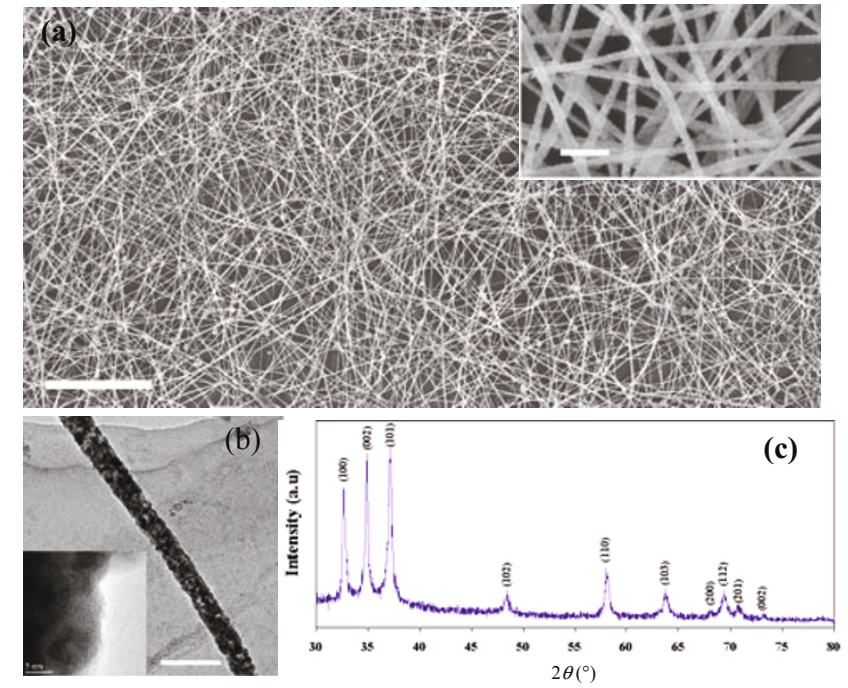

Fig. 5 (a) SEM image of synthesized GaN nanofibers. Scale bar: $5 \mu \mathrm{m}$. Inset: SEM image with higher magnification. Scale bar: $200 \mathrm{~nm}$. (b) TEM image of a single $\mathrm{GaN}$ nanofiber. Scale bar: $100 \mathrm{~nm}$. Upper inset depicts a corresponding EDX pattern, lower left inset is a high-resolution TEM image. Scale bar: $5 \mathrm{~nm}$. (c) XDR pattern of synthesized nanofibers [50]. Reprinted with permission from $\mathrm{Wu} \mathrm{H}$, Lin $\mathrm{D}$ D, Zhang R, Zhang C. Pan W, Adv. Mater. 2009; 21: 227-231. Copyright 2009 WILEY-VCH Verlag GmbH \& Co. KGaA, Weinheim 
high resolution TEM image indicates that the crystalline size of the nanofiber is less than $10 \mathrm{~nm}$ (insets of Fig. 5b). This approach will be applicable to the synthesis of other nitride nanofibers such as InN, AlN, and InGaN. It is expected that this technique will make the large-scale production and assembly of nitride functional nanomaterials with practical applications possible [50].

Lin et al. demonstrated that using the electrospinning technique coupled with a thermal treatment approach, $\mathrm{ZnS}$ nanofibers can be prepared by sulfurizing the electrospun $\mathrm{ZnO}$ nanofibers (as a template) at $500{ }^{\circ} \mathrm{C}$ in an $\mathrm{H} 2 \mathrm{~S}$ atmosphere (Fig. 6) [38]. The $\mathrm{ZnS}$ nanofibers were found to be polycrystalline, with an average grain size of $20 \mathrm{~nm}$ (Fig. 6d). The morphology of $\mathrm{ZnS}$ nanofibers was found to be rough and uneven, which was considered to be correlated with the processing conditions. Their study demonstrated that electrospinning could be a general approach of fabricating 1D-nanostructured sulfide with rough surface and high surface area for potential applications in nanoscale devices like high performance sensors [38].

\section{Controlled assembly of ceramic nanofibers}

Well-aligned and highly ordered structures are often required for device applications, especially in the fabrication of electric and photonic devices like field effect transistors, sensors and diodes. Many approaches have been developed to control the alignment of electrospun nanofibers. Xia group developed a gap technique, as shown in Fig. 7a, by which one can collect the electrospun nanofibers as a uniaxially aligned arrays over a large area [24,27,29,30,32-34,88]. The setup is essentially the same as the conventional one except for the introduction of an insulating (e.g. made of air, quartz, or polystyrene) gap in the middle of the collector, with a width that can be varied from hundreds of micrometers to several centimeters. The insulating gap makes the electric field lines in the vicinity of the collector split into two fractions pointing toward opposite edges of the gap (see the electrostatic force analysis in Fig. 7b). The as-spun, charged nanofibers are expected to experience electrostatic forces from two sources: the strong external field (F1) between the spinneret and the collector, and the repulsion between adjacent, charged fibers (F2). As a result, the fibers are stretched perpendicular to the edges of the gap [33]. Since the fibers can keep highly charged after deposition, the strong repulsion between the deposited and incoming nanofibers can facilitate a parallel alignment between them as this alignment has the lowest energy. Therefore, the alignment can be significantly improved as the deposition is increased. By using this modified electrospinning technique, well-aligned ceramic nanofiber arrays (Fig. 7) or single nanofiber deposited in controlled directions can be fabricated.

Our group developed a newly modified electrospinning technique for generating highly oriented ceramic nanofibers with a length of several centimeters. Very different from the conventional electrospinning process, the fibers are collected between the electrodes [41]. The experimental configuration for our modified electrospinning setup is illustrated in Fig. 8a. Unlike the conventional setup, a metallic triangular tip without any solution supply system was used as the electrospinning source. The tip

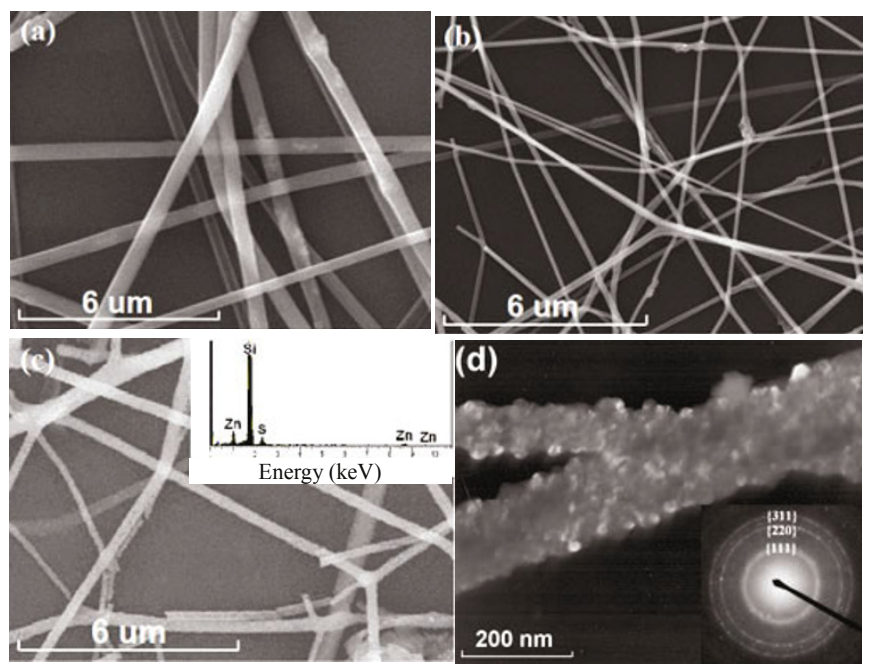

Fig. 6 SEM image of as-spun PVPzinc acetate composite nanofibers (a), after annealing at $500{ }^{\circ} \mathrm{C}$ in air for $1 \mathrm{~h}$ (b), after subsequent annealing at $500{ }^{\circ} \mathrm{C}$ in a $\mathrm{H}_{2} \mathrm{~S}$ atmosphere for $2 \mathrm{~h}$ (c), and a dark-field transmission electron microscopy image there of (d). An energy-dispersive X-ray spectroscopy result and electron-diffraction pattern recorded from the $\mathrm{ZnS}$ nanofibers are inserted, respectively [38]. Reprinted with permission from Lin D D, Wu $\mathrm{H}$, Zhang R, Pan W, J. Am. Ceram. Soc. 2007; 90: 3664-3666. Copyright 2007 The American Ceramic Society 
was prepared by cutting down a 1-mm-thick aluminum sheet into a $1-5 \mathrm{~cm}$ rectangle with a triangular tip. The apex angle of the triangular was set as $60^{\circ}$. The tip was used as the electrospinning source; it helped to establish a Tylor cone while electrospinning. A grounded coin was placed close to the aluminum sheet as the counter electrode of the system. A bundle of aligned electrospun fibers was then formed between the spinning tip and the collector (Fig. 1c). The fibers were then transferred on a silicon wafer. The key to success is the reduction of interelectrode distance and the use of an ultra strong electric field, which is about six times higher than conventional conditions [41].

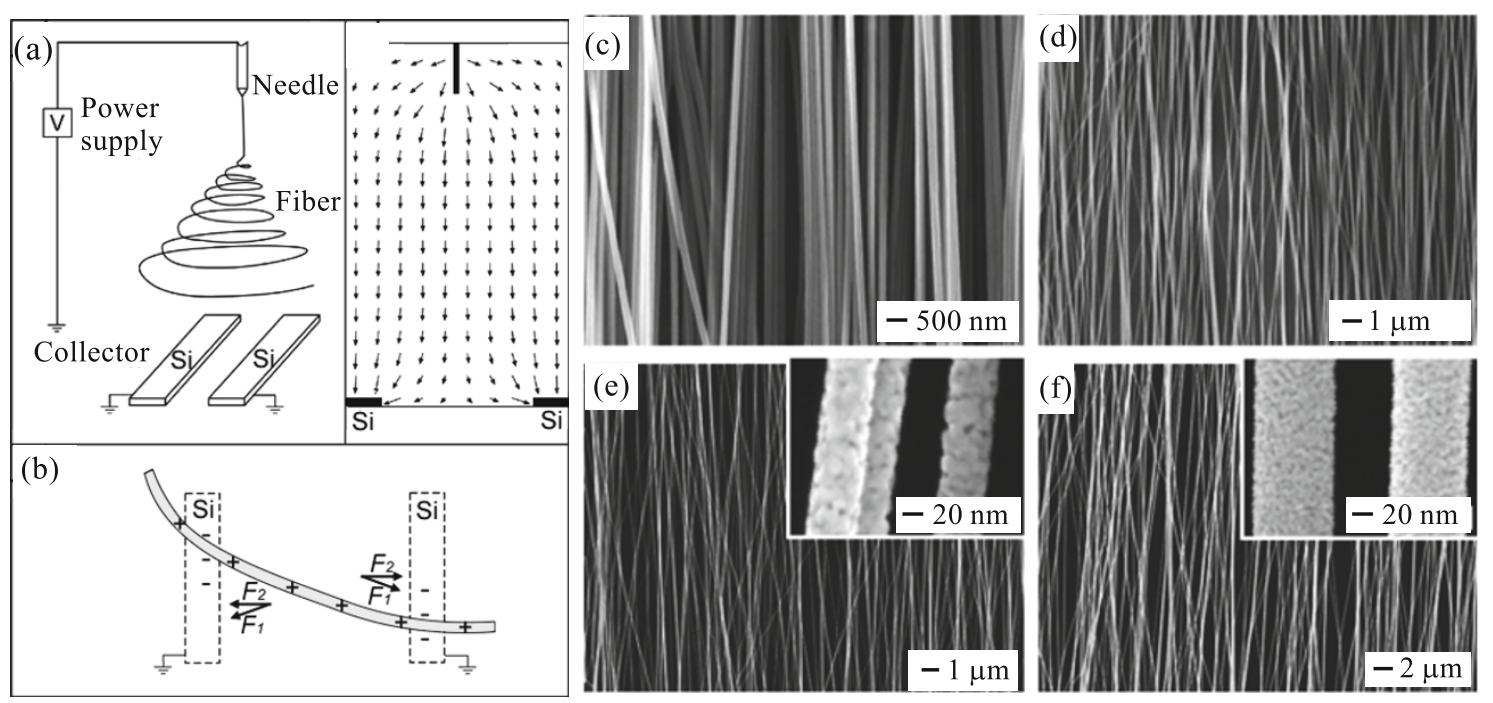

Fig. 7 (a) Schematic illustration of the setup for collecting nanofibers as a uniaxially aligned array. The collector contains an insulating void, such as the air gap between two strips of silicon wafers. (b) Electrostatic force analysis of a charged nanofiber spanning across two silicon strips. The orientation of the nanofiber is mainly controlled by the stretching force originating from the attractive electrostatic forces. (c)-(f) SEM images of uniaxially aligned nanofibers made of (c) carbon, (d) anatase $\mathrm{TiO}_{2}$, (e) $\mathrm{NiFe}_{2} \mathrm{O}_{4}$, (f) $\mathrm{TiO}_{2} / \mathrm{PVP}$ [29]. Reprinted with permission from Li D, Wang YL, Xia YN. Nano Lett 2003; 3: 1167-1171. Copyright 2003 American Chemical Society

(a)
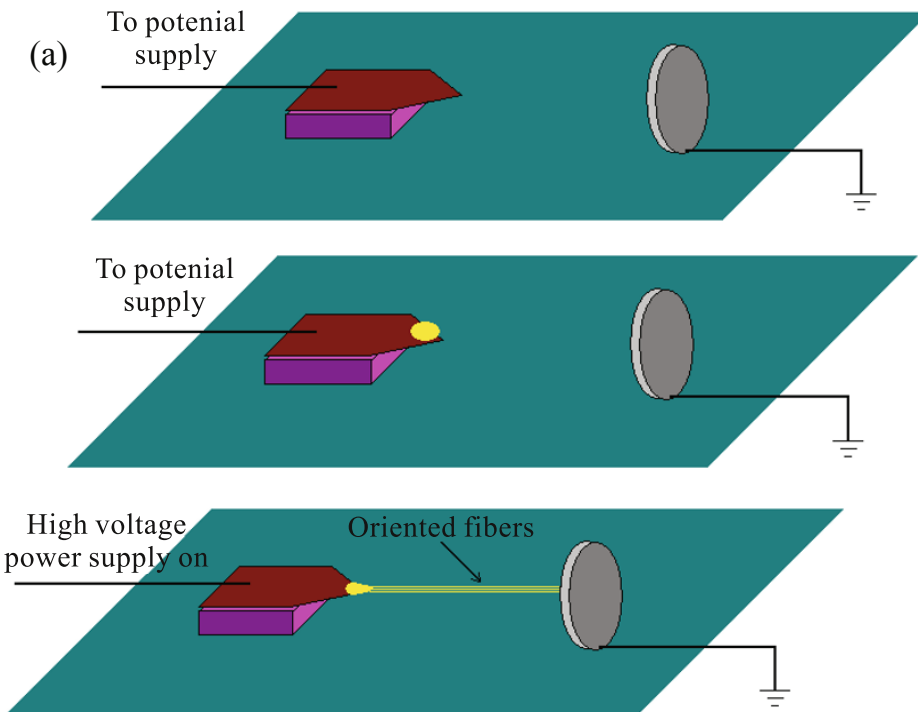

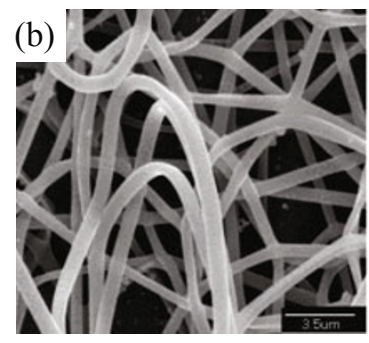

(c)

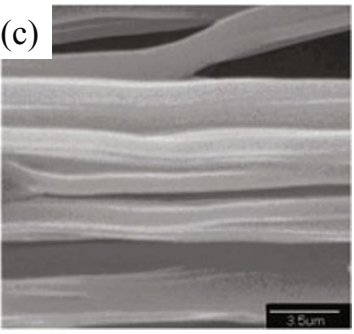

Fig. 8 (a) Schematic illustration of the modified electrospinning process for preparing aligned fibers. (b) SEM image of randomly arranged polyvinyl acetate (PVA)/zinc acetate composite fibers prepared by the conventional electrospinning method; (c)SEM images of random nanofibers and oriented fibers obtained by the modified electrospinning method [41]. Reprinted with permission from Wu H, Lin D D, Zhang R, Pan W. J Am Ceram Soc 2007; 90: 632-634. Copyright 2006 The American Ceramic Society 


\section{Properties and applications}

\subsection{Electrical transfer properties and FET devices}

Our group reported the assembly and electrical properties of ultralong copper oxide $(\mathrm{CuO})$ nanofibers prepared by electrospinning method [35]. The prepared $\mathrm{CuO}$ nanofibers were polycrystalline, with diameter of $60 \mathrm{~nm}$ and length over $100 \mu \mathrm{m}$. By using a designed fiber collector, the electrospun $\mathrm{CuO}$ nanofiber was deposited bridging two paralleled electrodes. Electrical measurement was conducted between the two electrodes. The conductivity of individual $\mathrm{CuO}$ nanofiber was measured to be $3 \times 10^{-3} \mathrm{~S} / \mathrm{cm}$. Field effect transistor behavior in single $\mathrm{CuO}$ nanofiber was also observed, showing that $\mathrm{CuO}$ nanofiber was intrinsic p-type semiconductor [35]. Another research in our group performed electrical measurement on single $\mathrm{ZnO}$ nanofibers. FET behavior in single $\mathrm{ZnO}$ nanofiber was also observed, showing that the $\mathrm{ZnO}$ nanofiber was an intrinsic n-type semiconductor [43].

Highly oriented GaN nanofibers were fabricated by electrospinning. This technique indicated the possibility of precisely locating a patterned $\mathrm{GaN}$ nanofiber with designed orientation, which is favorable for some practical applications such as electrical devices and lasers [50]. As an example, we assembled a single electrospun GaN nanofiber into a field-effect transistor device, which is schematically shown in the inset of Fig. 9d. The current-voltage $\left(\mathrm{I}_{\mathrm{sd}}-\mathrm{V}_{\mathrm{sd}}\right)$ characteristics of a GaN nanofiber FET device at different gate voltages (from $+60 \mathrm{~V}$ to $-60 \mathrm{~V}$ with a $30 \mathrm{~V}$

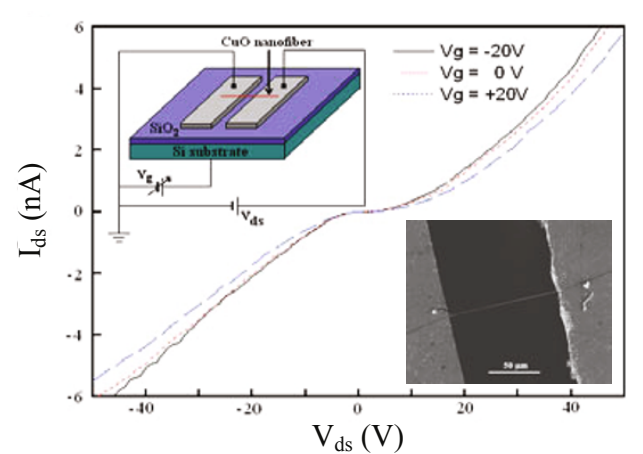

(a)

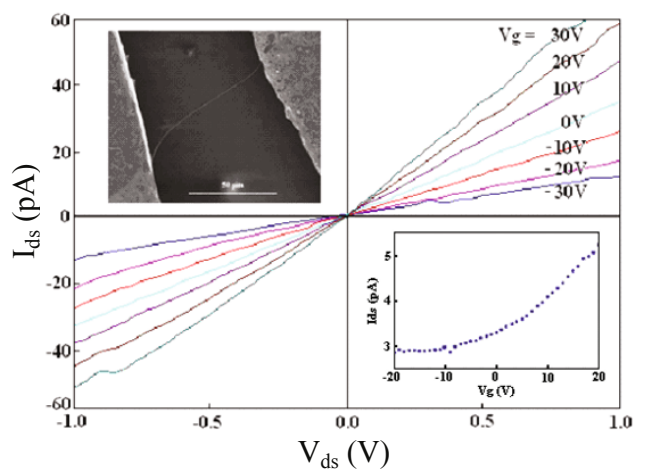

(c)

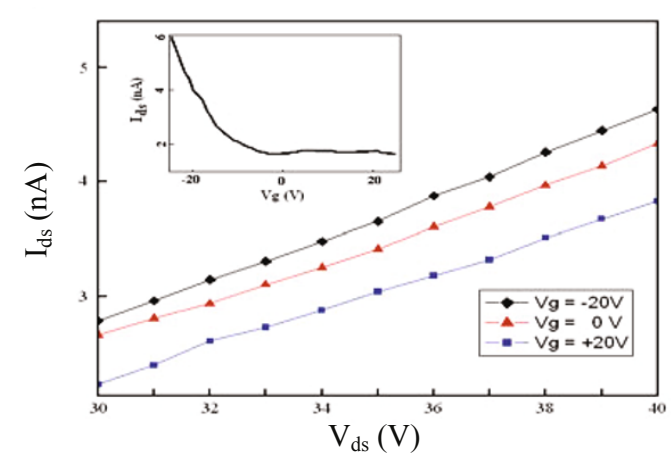

(b)

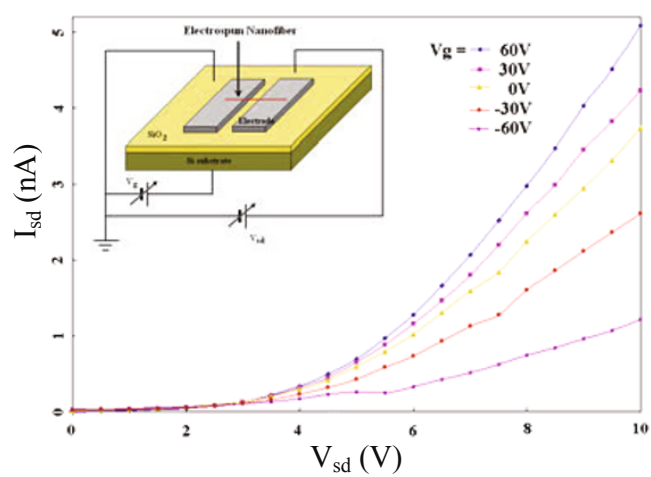

(d)

Fig. 9 (a) Gate-dependent $\mathrm{I}-\mathrm{V}$ measurement of a single $\mathrm{CuO}$ nanofiber contacted with $\mathrm{Ag}$ electrodes. Measurements were done at room temperature. Upper inset: Schematic view of a nanofiber FET configuration. The source and drain contacts are silver stripes, and heave doped p-type Si substrate serves as the back gate. Bottom inset: FE-SEM image of a $60 \mathrm{~nm}$ diameter $\mathrm{CuO}$ nanofiber with a length of $\sim 100 \mu \mathrm{m}$ suspending across the silver electrodes. (b) Enlarged plot of (a). Inset: Current Ids vs gate voltage Vg at $V_{\mathrm{ds}}=0 \mathrm{~V}$. (c) Gate-dependent I-V measurement of a single $\mathrm{ZnO}$ nanofiber. (d) Gate-dependent $\mathrm{I}-\mathrm{V}$ measurement of a single GaN nanofiber contacted with Ag electrodes [35,43,50]. Panel a and b reprinted with permission from Wu H, Lin D D, Pan W. Appl Phys Lett 2006; 89, 133125. Copyright 2006 American Institute of Physics. Panel c reprinted with permission from Wu H, Lin D D, Zhang R, Pan W, J. Am. Ceram. Soc. 2008; 91: 656-659. Copyright 2007 The American Ceramic Society. Panel d reprinted with permission from Wu H, Lin D D, Zhang R, Zhang C. Pan W, Adv. Mater. 2009; 21: 227-231. Copyright 2009 WILEY-VCH Verlag GmbH \& Co. KGaA, Weinheim 
step) are shown in Fig. 9d. The current versus source-drain voltage and gate voltage were measured, the nanofiber conductance increases for $\mathrm{Vg}$ greater than zero and decreases for $\mathrm{Vg}$ less than zero, which indicates that these nanofibers are intrinsic n-type. This n-type behavior in nominally undoped $\mathrm{GaN}$ is believed to be attributed to the nitrogen vacancies and/or oxygen impurities [50].

Our results indicated that semiconductive ceramic nanofibers can be directly assembled into FETs using the simple and versatile electrospinning method. The nanofiber transistors should be useful in building low-cost logic and switching circuits, as well as highly sensitive chemical and biological sensors with reduced device dimensions.

It is of great interest to study oxide nanofibers with doping of selection of elements for enhancing and controlling their mechanical, electrical, and optical performance. Our group studied the electrical properties of single aluminum-doped zinc oxide nanofibers [16]. Typical current-voltage (I-V) curve through a single AZO nanowire with different $\mathrm{Al}$ concentrations is shown in Fig. 10, and the

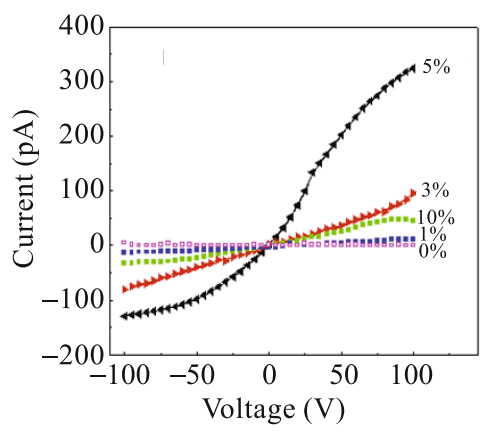

(a)

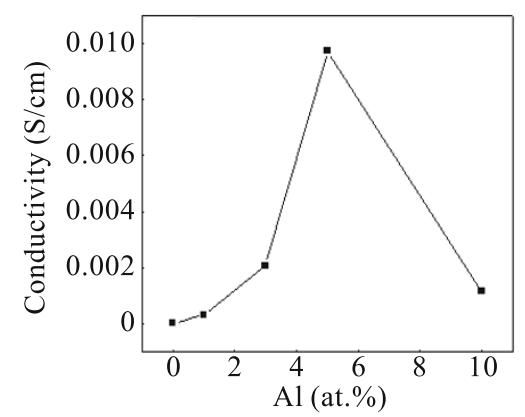

(b)

Fig. 10 (a) The measured current-voltage (I-V) curves of undoped and $\mathrm{Al}$-doped samples; (b) $\mathrm{Al}$ at $\%$ dependent conductivity of AZO nanowires [16]. Reprinted with permission from Lin $\mathrm{D}, \mathrm{Wu} \mathrm{H}$, Pan W. Advanced Materials 2007; 19: 3968-3972. Copyright 2007 WILEYVCH Verlag GmbH \& Co. KGaA, Weinheim corresponding conductivity was calculated (Fig. 10). Compared to the pure $\mathrm{ZnO}$ nanowire with a conductivity of $2.55 \times 10^{-5} \mathrm{~S} \mathrm{~cm}^{-1}$, the Al-doped $\mathrm{ZnO}$ nanowires show a steep increase up to $9.73 \times$ $10^{-3} \mathrm{~S} \mathrm{~cm}^{-1} \quad(\mathrm{Al}=5$ at $\%)$, indicating a great enhancement in conductivity. Here, aluminum acts as a cationic dopant in the $\mathrm{ZnO}$ lattice, that is, the trivalent $\mathrm{Al}^{3+}$ ion will occupy the divalent $\mathrm{Zn}^{2+}$ site allowing electrons to move to the conduction band easily. This gives a net increase in the concentration of electrons, thereby enhancing the electrical conductivity [16]. Lin et al. studied electrical transfer properties of indium doped tin oxide (ITO) nanofibers [37]. Devices for I-V measurement and field-effect transistors (FETs) were assembled using ITO nanowires with top contact configurations. The effect of Sn doping on the electrical conductivity was significant in that it enhanced the conductance by over $10^{7}$ times, up to $\sim 1 \mathrm{~S} \mathrm{~cm}^{-1}$ for ITO nanowires with an Sn content of 17.5 at.\%. The nanowire FETs were operated in the depletion mode with an electron mobility of up to $0.45 \mathrm{~cm}^{2} \mathrm{~V}^{-1} \mathrm{~s}^{-1}$ and an on/off ratio of $10^{3}$.

\subsection{Optical properties and photo sensors}

Electrospun inorganic nanofibers have interesting optical properties due to its shrinked dimensions and nanoscale grain sizes. For example, our group studied the photoluminescence (PL) spectroscopy of electrospun GaN nanofibers [50]. Spectra were collected at room temperature, exited by a monochromatic source with excitation energy of 3.82 $\mathrm{eV}(325 \mathrm{~nm})$. The PL spectrum (Fig. 11a) from GaN nanofibers showed a broad peak at $363 \mathrm{~nm}(3.42 \mathrm{eV})$, and a small, narrow peak at $333 \mathrm{~nm}(3.72 \mathrm{eV})$. It is known that the size effect widens the bandgap of nanowires and that a blue-shift may occur to the PL spectrum; however, surface effects narrow the bandgap of nanowires. According to our experimental results, the primary bandgap of the nanofibers $(3.42 \mathrm{eV})$ is a little higher than that reported for bulk GaN (Wurtzite: $3.4 \mathrm{eV}$ ), which indicates a combination of the size effect and surface effect. As ammonia exists during the fabrication of $\mathrm{GaN}$ nanowires, surface passivation of $\mathrm{GaN}$ nanowires may exist, and accordingly modifies the bandgap, as reported for other nitride nanowires. The small peak at $333 \mathrm{~nm}$ demonstrated a blue-shift in the emission photon energy of the nanoparticles compared with the bandgap of bulk GaN, which shows that the emission peak is a result of the quantum 


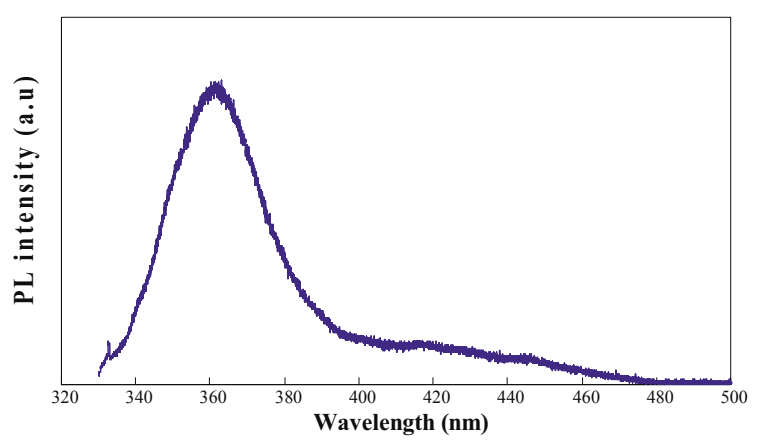

(a)

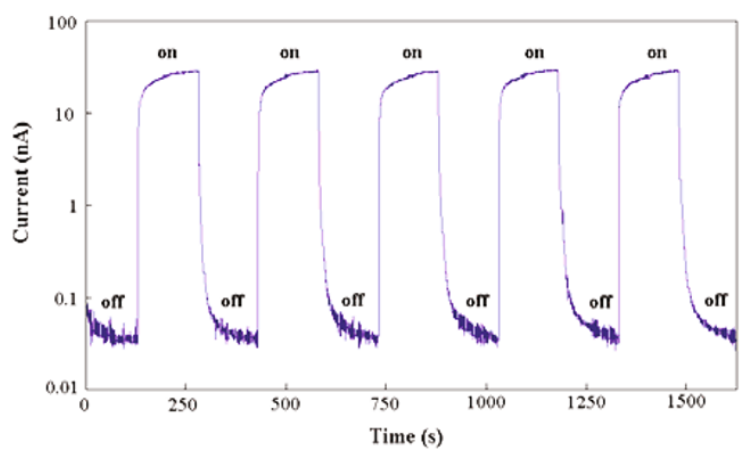

(b)

Fig. 11 (a) Room temperature PL spectrum of GaN nanofibers. The excitation wavelength is $325 \mathrm{~nm}$ from a He-Cd laser. (b) Conductance response of a GaN nanofiber upon pulsed illumination from a $254 \mathrm{~nm}$ wavelength UV light with a power density of $3 \mathrm{Mwcm}^{-2}$ [50]. Reprinted with permission from Wu H, Lin D D, Zhang R, Zhang C. Pan W, Adv. Mater. 2009; 21: 227-231. Copyright 2009 WILEY-VCH Verlag GmbH \& Co. KGaA, Weinheim

confined states in GaN nanoparticles. Considering the wide direct band gap, nanometer-scale dimensions, and also taking advantage of the high aspect ratio and rough surfaces, electrospun ceramic nanofibers are suitable for ultraviolet photodetection applications [50]. Figure $11 \mathrm{~b}$ shows the photoconductance response of the GaN nanofiber FET device fabricated by $\mathrm{Wu}$ et al. The measured Isd of the nanofiber device showed a rapid increase from about 0.03 to $25 \mathrm{nA}$ upon exposure. The electrospun $\mathrm{GaN}$ nanofibers show much higher sensitivity to UV detection than that of single crystalline GaN nanowires. From their measurement data, the conductance of an electrospun $\mathrm{GaN}$ nanofiber increases by 830 times when UV was on. In contrast, a single crystal GaN nanowire grown by the chemical vapour deposition (CVD) method showed a smaller response $(\sim 78)$ to UV light [50]. A similar enhancement of photoresponse within electrospun ceramic nanofibers has also been demonstrated in $\mathrm{Ag} / \mathrm{ZnO}$ and $\mathrm{AZO}$ material systems. For example, photoactive material consisting of heterogeneous $\mathrm{Ag}-\mathrm{ZnO}$ nanowires and nanofibers was prepared by electrospinning by Lin et al. Tunable UV photodetectors fabricated using $\mathrm{Ag}-\mathrm{ZnO}$ NWs have shown high sensitivity up to over four orders of magnitude with relatively fast and stable response speed (Fig. 12) [48]. In conclusion, electrospun nanofibers is suitable for assembling next generation high-performance photo-sensor devices due to its unique polycrystalline nature and rough surfaces, which lead to a high surface area-to-volume ratio, and subsequently result in more photo generated carriers compared with a smooth single crystalline nanowires.

\subsection{Memory device}

Electrospun ceramic nanofibers have been assembled to functional nano-scale smart electronic devices including but not limited to FETs and sensors. Lin et al. developed single $\mathrm{ZnO}$ nanofiber based memories. A nanoscale memory device constructed from an individual AZO nanowire was observed to switch between two states differing in conductivity by about one order of magnitude, because of field-induced charge trapping and de-trapping (Fig. 13) [16]. These results demonstrate that multifunctional AZO nanostructures prepared by electrospinning have great potential applications in next-generation semiconductor devices, such as diodes and photodetectors, as well as transparent sensors and memories.

\subsection{Magnetic properties}

Magnetic properties of ceramic nanofiber systems have been widely studied [55,61,89-93]. For example, Fe-doped $\mathrm{TiO}_{2}-\mathrm{SnO}_{2}$ hybrid nanofiber has been prepared via electrospinning method. The magnetic property versus Fe doping content was characterized ${ }^{55}$. The magnetic properties have also been characterized for the $\mathrm{Fe}-\mathrm{TiO}_{2} / \mathrm{SnO}_{2}$ nanofibers before and after annealing under vacuum atmosphere, and nanofibers show obvious ferromagnetic property at room temperature as they are annealed (Fig. 14a) [55]. Wu el al. showed that the simple solution-based electrospinning synthetic method allows convenient assembly and precise doping of $\mathrm{Mn}$ or other elements into the $\mathrm{GaN}$ nanofiber matrix and the Mn-doped $\mathrm{GaN}$ 


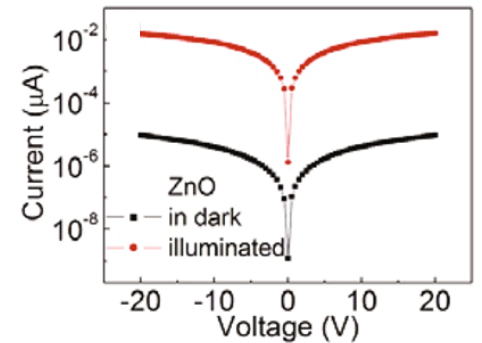

(a)

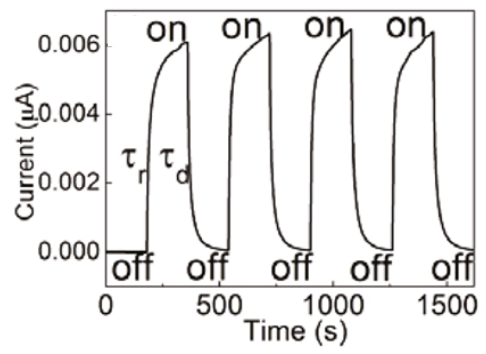

(c)

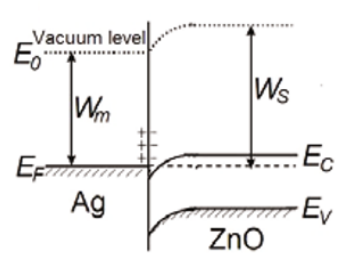

(e)

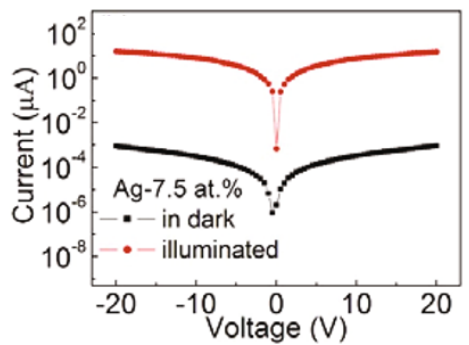

(b)

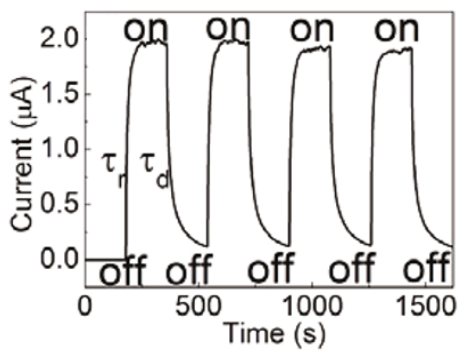

(d)

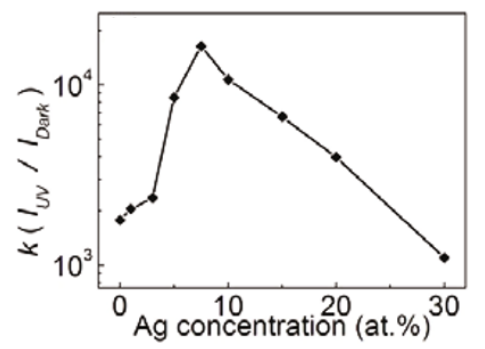

(f)

Fig. 12 Typical $\mathrm{I}-\mathrm{V}$ characteristics of dark current and photocurrent through individual nanowires under UV illumination $\lambda=254 \mathrm{~nm}$ : (a) $\mathrm{ZnO}$; (b) 7.5 at. \% Ag-ZnO. Time-dependent photore sponses at a bias voltage of $4 \mathrm{~V}$ : (c) $\mathrm{ZnO}$; (d) 7.5 at. \% Ag-ZnO. (e) Proposed schematic illustrations of the energy band structure of the Ag- $\mathrm{ZnO}$ heterostructure. (f) Dependence of photosensitivity $k$ on Ag loadings, where $k$ is defined as the ratio of photocurrent to dark current that measured at $4 \mathrm{~V}$, respectively [48]. Reprinted with permission from Lin D D, Wu H, Zhang W, et al. Appl Phys Lett 2009; 94: 172103. Copyright 2006 American Institute of Physics
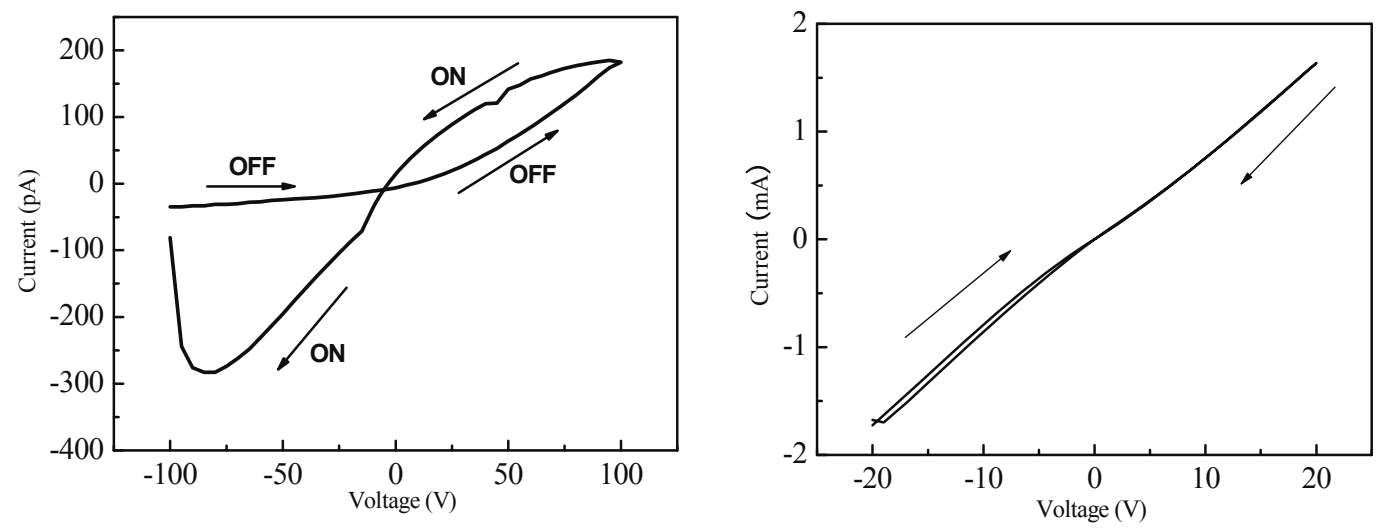

Fig. 13 (a) Memory characteristics of the AZO nanowires ( $\mathrm{Al}$ at \%=3\%). (b) Current-voltage (I-V) curves of the AZO film with $200 \mathrm{~nm}$ thickness. Reprinted with permission from Lin D, Wu H, Pan W. Advanced Materials 2007; 19: 3968-3972. Copyright 2007 WILEY-VCH Verlag GmbH \& Co. KGaA,Weinheim 


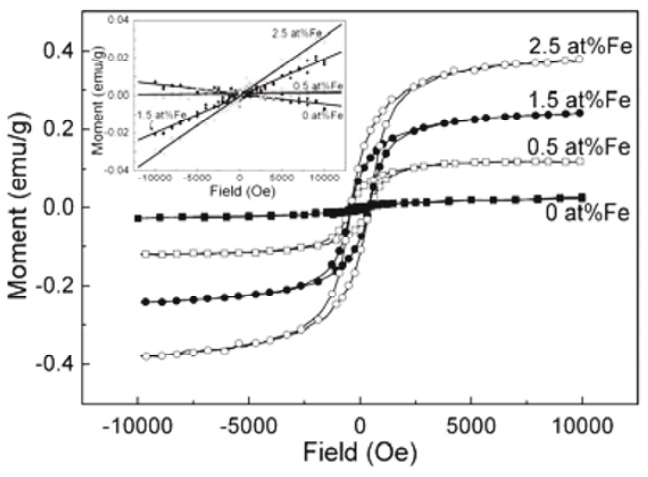

(a)

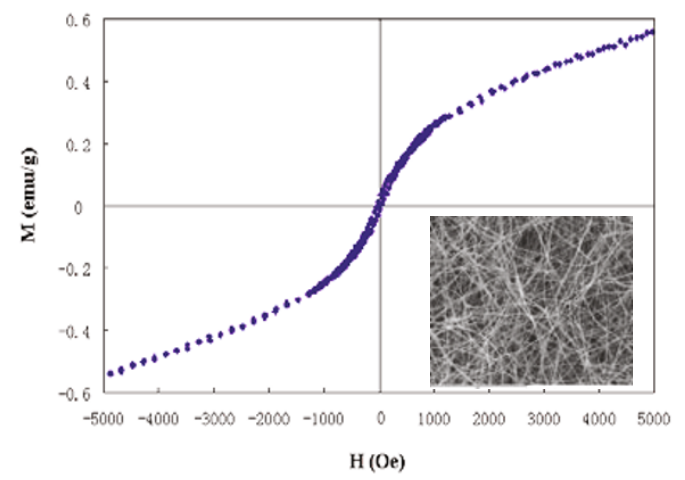

(b)

Fig. 14 (a) Magnetic hysteresis loops of $\mathrm{Fe}-\mathrm{TiO}_{2} / \mathrm{SnO}_{2}$ hybrid nanofibers after vacuum annealing. Inset shows the magnetic property of them before vacuum annealing [55]. (b) Magnetization loops of the nanofibers measured at room temperature. Inset shows a typical SEM image of the samples. Scale bar is $1 \mu \mathrm{m}$ [50]. Panel a reprinted with permission from Zhang R, Wu H, Lin DD, et al. J Am Ceram Soc 2010; 93: 605-608. Copyright 2009 The American Ceramic Society. Panel b reprinted with permission from Wu H, Lin D D, Zhang R, Zhang C. Pan W, Adv. Mater. 2009; 21: 227-231. Copyright 2009 WILEY-VCH Verlag GmbH \& Co. KGaA, Weinheim

nanofibers show ferromagnetic character at room temperature (Fig. 14b) [50]. Their result shows a new way to the facile synthesis of diluted magnetic semiconductor (DMS) nanofibers, which is of significant importance for constructing spintronic nanodevices such as ultrasensitive magnetic field sensors and spin FETs.

\subsection{Phase transition}

Nano-structured ceramics are also suggested to have different thermal stabilities compared with their bulks due to the shrinked dimensions and size effects. Our group studied the phase stability of ferroelectric and piezoelectric ceramic nanofibers. $\mathrm{BaTiO}_{3}$ nanofibers with diameters ranging from 92 to $182 \mathrm{~nm}$ have been prepared by electrospinning [45]. XRD and SEM revealed that when the annealing temperature is higher than $600{ }^{\circ} \mathrm{C}$, completely crystallized $\mathrm{BaTiO}_{3}$ nanofibers could be obtained and the grain size almost kept a constant value $(\sim 13.7 \mathrm{~nm})$ when the annealing time lasted longer than $8 \mathrm{~h}$ at $600{ }^{\circ} \mathrm{C}$. Besides, the diameters of fibers decreased when the annealing temperature increased from 500 to $600{ }^{\circ} \mathrm{C}$, but at elevated temperature higher than $600{ }^{\circ} \mathrm{C}$, the fibers became thicker and also exhibited a rougher surface feature. Tetragonal to cubic phase transition in BTO nanofibers were monitored using Raman spectroscopy (Fig. 15). They found that the electrospun $\mathrm{BaTiO}_{3}$ nanofibers have much higher $\mathrm{Tc}\left(\sim 220^{\circ} \mathrm{C}\right)$ than bulk $\mathrm{BaTiO}_{3}$ ceramics $\left(\sim 130{ }^{\circ} \mathrm{C}\right)[45]$. This effect can be understood by considering the shrinked sizes in $\mathrm{BaTiO}_{3}$ nanofibers.
The reduced grain size in electrospun $\mathrm{BaTiO}_{3}$ nanofibers caused larger grain-boundary areas, and further relieved internal stresses in materials due to grain-boundary sliding. Smaller internal stresses, relaxed by grain boundaries, could decrease the free energy of the ferroelectric phase, and thus increase the Curie temperature. Our research indicates that electrospinning ceramic nanofibers may have different phase stability of ceramics than in bulks, which provides an exciting opportunity for controlling the electrical, optical and ferroelectric performance of ceramics.

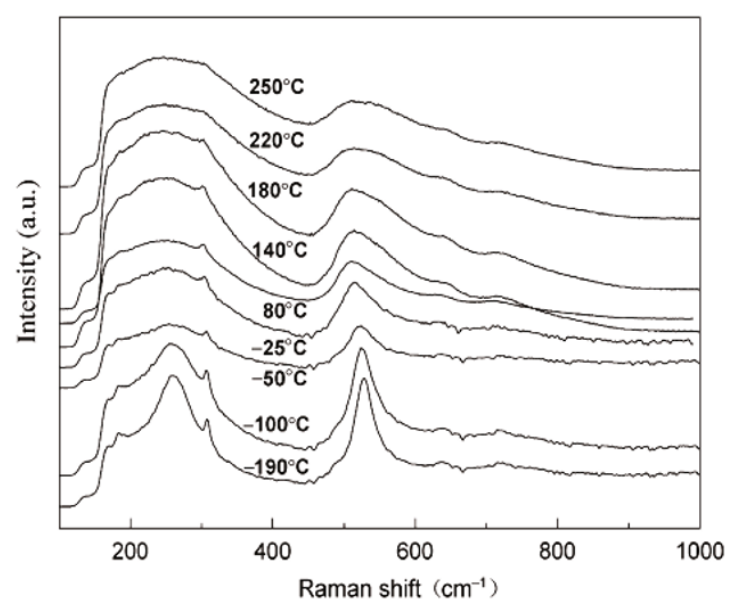

Fig. 15 Raman spectra of $\mathrm{BaTiO}_{3}$ nanofibers at various temperatures [45]. Reprinted with permission from Li H P, Wu H, Lin D D, et al. J Am Ceram Soc 2009; 92: 2162-2164. Copyright 2009 The American Ceramic Society 


\subsection{Energy storage}

Electrospinning ceramic nanofiber, which has extremely high surface area according to its small size and provides fast charge-transfer channels along its 1D nanostructure, has been considered as an ideal material system for energy storage applications [94-138]. For example, Mai et al. demonstrated high performance lithium ion battery electrode based on electrospun vanadium oxide nanofibers [133]. They prepared ultralong hierarchical vanadium oxide nanowires with diameter of 100-200 $\mathrm{nm}$ and length up to several millimeters using the low-cost starting materials by electrospinning combined with annealing. The hierarchical nanowires were constructed from attached vanadium oxide nanorods of diameter around $50 \mathrm{~nm}$ and length of $100 \mathrm{~nm}$. The initial and 50th discharge capacities of the ultralong hierarchical vanadium oxide nanowire cathodes are up to 390 and $201 \mathrm{mAh} / \mathrm{g}$ when the lithium ion battery cycled between 1.75 and 4.0 $\mathrm{V}$ (Fig. 16). When the battery was cycled between 2.0 and $4.0 \mathrm{~V}$, the initial and 50th discharge capacities of the nanowire cathodes are 275 and $187 \mathrm{mAh} / \mathrm{g}$. Compared with self-aggregated short nanorods synthesized by hydrothermal method, the

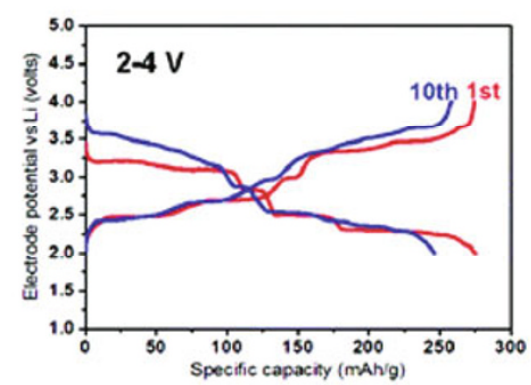

(a)

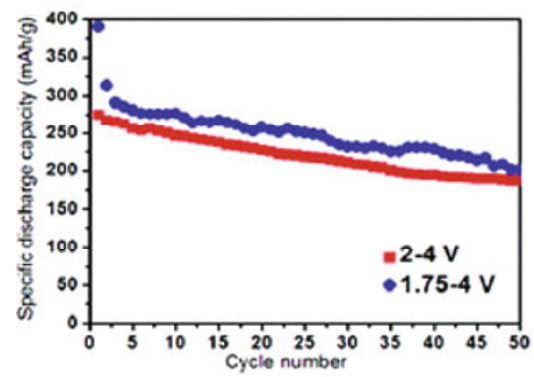

(c) ultralong hierarchical vanadium oxide nanowires exhibit much higher capacity. This is due to the fact that self-aggregation of the unique nanorod-innanowire structures has been greatly reduced because of the attachment of nanorods in the ultralong nanowires, which can keep the effective contact areas of active materials, conductive additives, and electrolyte large and fully realize the advantage of nanomaterial-based cathodes. This demonstrates that ultralong hierarchical vanadium oxide nanowire is one of the most favorable nanostructures as cathodes for improving cycling performance of lithium ion batteries [133].

\subsection{Photo catalyst}

Environmental problems such as air and water pollution have provided the impetus for sustained fundamental and applied research in the area of environmental remediation [139-144]. With the steady and fast growing field of nanoscience and nanotechnology, nanostructured ceramics like zinc oxide and titanium oxide has become a promising photocatalyst for its high catalytic activity, low cost, and environmental friendliness $[50,51,55,57$,

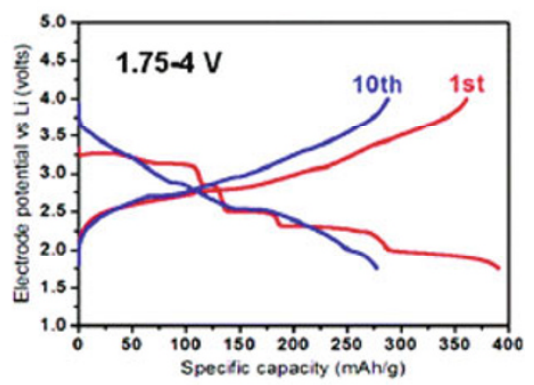

(b)

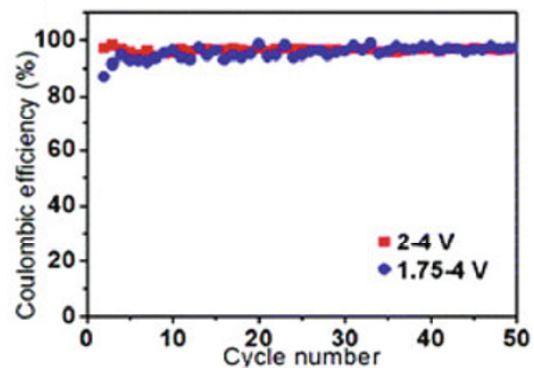

(d)

Fig. 16 (a), (b) Charge/discharge curves of hierarchical vanadium oxide nanowires at voltages of 2-4 and 1.75-4 V, respectively. (c), (d) Capacity vs cycle number, and Coulombic efficiency vs cycle number of the ultralong hierarchical vanadium oxide nanowires [133]. Reprinted with permission from Mai L Q, Xu L, Han C H, et al. Nano Lett 2010; 10: 4750-4755. Copyright 2010 American Chemical Society 
139-142,145-152]. Major limitation of achieving high photocatalytic efficiency in the ceramic nanostructure systems is the quick recombination of charge carriers. Electrospinning ceramic nanofibers have extremely high surface area due to its small sizes, and further provide channels for quick charge transfer due to its 1D nanostructures. Therefore, electrospun ceramics have huge potential for photo catalyst applications [47, 57,145-155]. Our group fabricated photocatalytically active $\mathrm{Ag}-\mathrm{ZnO}$ composite nanofibers by electrospinning (Fig. 17) [47]. The resultant heterostructure could promote the charge separation of the photogener ated electrons (e-) and holes $(\mathrm{h}+)$, allowing both of the e- and $\mathrm{h}+$ participating in the overall photocatalytic reaction. The optimal photocatalytic activity of $\mathrm{Ag}-\mathrm{ZnO}$ nanofibers exceeded that of pure $\mathrm{ZnO}$ nanofibers by a factor of more than 25 when the Ag concentration was kept at 7.5 atom \%. Therefore, exploring the catalytic activity of such composite structures may pave the way for designing useful nanoscale building blocks for photocatalytic and photovoltaic applications [47]. Zhang et al. synthesized hybrid $\mathrm{Fe}-\mathrm{TiO}_{2} / \mathrm{SnO}_{2}$ nanofibe with combination of high photocatalytic activity and room temperature ferromagnetic properties. It is believed that this hybrid nanofiber may serve as a candidate of new generation of visible light-excitable photocatalyst, which is also possibly easy for recycling and its potential applications are foreseeable in some fields such as water purifying and pollution treatment [55].

\subsection{Filters and separators}

Taking advantages of the highly porous fibrous nanostructures, ceramic nanofiber membrane can be used for filter and separator applications [128,156-159]. For example, Ke et al. demonstrate high performance filters by constructing a hierarchically structured

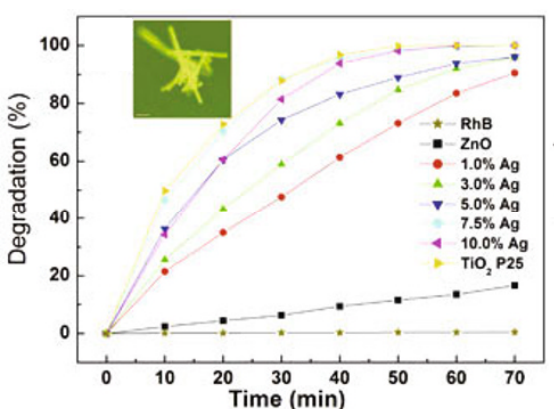

(a)

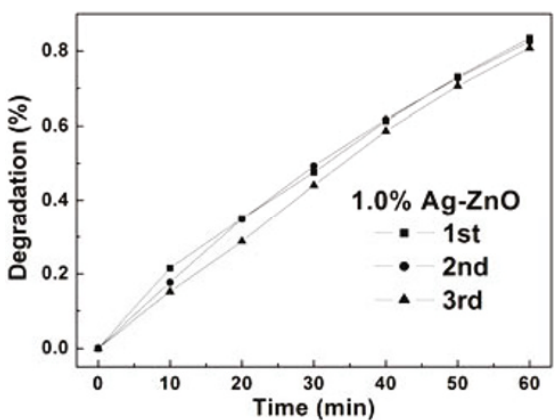

(c)

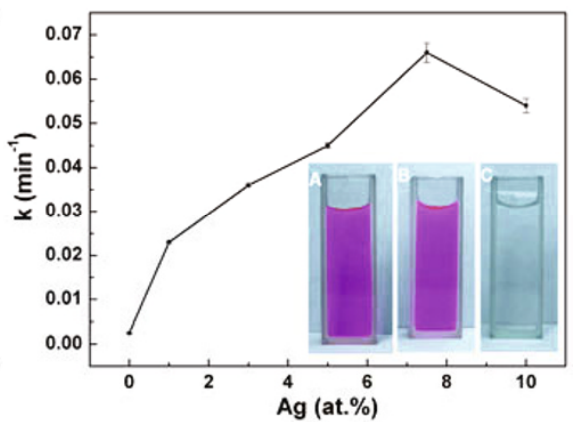

(b)

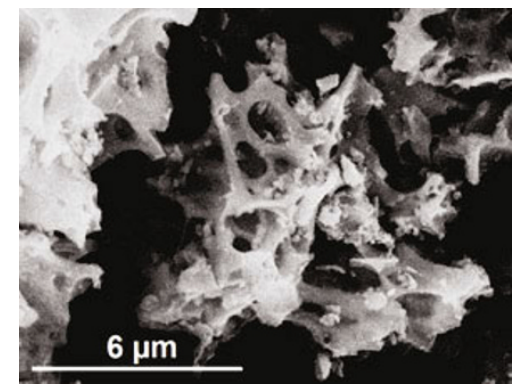

(d)

Fig. 17 (a) Kinetics of the photodegradation of an aqueous solution of $\mathrm{RhB}$ by $\mathrm{Ag}-\mathrm{ZnO}$ heterojunction nanofibers. The inset was the typical morphology of the photocatalyst dispersed in the dye solution (scale bar: $5 \mu \mathrm{m}$ ). (b) Degradation rate constants for $\mathrm{Ag}-\mathrm{ZnO}$ nanofibers obtained in the presence of different $\mathrm{Ag}$ contents (the inset illustrates photos for comparison of the RhB solutions photodegraded with various $\mathrm{Ag}-\mathrm{ZnO}$ nanofibers for $70 \mathrm{~min}$; $\mathrm{A}$, without catalyst; $\mathrm{B}$, pure $\mathrm{ZnO}$; and $\mathrm{C}$, $7.5 \mathrm{atom} \% \mathrm{Ag}-\mathrm{ZnO}$ ). (c) The repeatability tests studied on the $1.0 \mathrm{atom} \% \mathrm{Ag}-\mathrm{ZnO}$ sample for three recycles. (d) The SEM image of the sample reclaimed after photocatalytic measurement [47]. Reprinted with permission from Lin D D, Wu H, Zhang R, Pan W, Chem. Mater. 2009; 21: 3479-3484. Copyright 2009 American Chemical Society 
separation layer on a porous substrate using large titanate nanofibers and smaller boehmite nanofibers [157]. Traditional ceramic separation membranes, which are fabricated by applying colloidal suspensions of metal hydroxides to porous supports, tend to suffer from pinholes and cracks that seriously affect their quality. Other intrinsic problems for these membranes include dramatic losses of flux when the pore sizes are reduced to enhance selectivity and dead-end pores that make no contribution to filtration. Electrospun ceramic nanofiber mats can successfully overcome these challenges. The ceramic nanofibers are able to divide large voids into smaller ones without forming dead-end pores and with the minimum reduction of the total void volume. The separation layer of nanofibers has a porosity of over $70 \%$ of its volume, whereas the separation layer in conventional ceramic membranes has a porosity below $36 \%$ and inevitably includes deadend pores that make no contribution to the flux. This radical change in membrane texture greatly enhances membrane performance. The resulting membranes were able to filter out $95.3 \%$ of $60-\mathrm{nm}$ particles from a $0.01 \mathrm{wt} \%$ latex while maintaining a relatively high flux of between 800 and $1000 \mathrm{~L} /\left(\mathrm{m}^{2} \cdot \mathrm{h}\right)$, under a low driving pressure $(20 \mathrm{kPa})$. Such flow rates are orders of magnitude greater than those of conventional membranes with equal selectivity. Moreover, the flux was stable at approximately $800 \mathrm{~L} /\left(\mathrm{m}^{2} \cdot \mathrm{h}\right)$ with a selectivity of more than $95 \%$, even after six repeated runs of filtration and calcination. Use of different supports, either porous glass or porous alumina, had no substantial effect on the performance of the membranes; thus, it is possible to construct the membranes from a variety of supports without compromising functionality. The Darcy equation satisfactorily describes the correlation between the filtration flux and the structural parameters of the new membranes. The assembly of nanofiber meshes to combine high flux with excellent selectivity is an exciting new direction in membrane fabrication.

\section{Conclusions and future perspective}

Electrospun nanofibers are extremely long. Such high-aspect-ratio nanofibers made of ceramics provide an exciting materials system to investigate some fundamentally important problems, especially electrical, mechanical, magnetic and optical phenomena at the nanometer scale in ceramic science. Most ceramic nanofibers prepared by electrospinning are polycrystalline, which is quite different from CDV-grown single crystalline inorganic nanowires. The grain or domain size can be comparable with the diameter of the fibers, and may further provide unique functions like modified phase stability and high sensitivity to environmental. The electrospun nanofibers can be easily assembled for device integrations, which is important for future smart electronic devices in nanoscale. Another obvious advantage for electrospinning ceramic nanofibers is that the fabrication process is highly efficient and scalable. The low cost electrospun nanofibers hold potential for applications in photocatalyst and lithium ion battery electrodes. As both electrospinning and sol-gel processing techniques are being constantly improved, it is expected that progress in understanding the properties and applications of ceramic nanofibers will be accelerated in the coming years.

Open Access This article is distributed under the terms of the Creative Commons Attribution License which permits any use, distribution, and reproduction in any medium, provided the original author(s) and source are credited.

\section{Acknowledgment}

This study was supported by the National Natural Science Foundation of China (Nos. 50872063, 50990302, and 51072088).

\section{References}

[1] Palacios T. Applied physics nanowire electronics comes of age. Nature 2012, 481: 152-153.

[2] Yan H, Choe HS, Nam SW. Programmable nanowire circuits for nanoprocessors. Nature 2011, 470: 240-244.

[3] Yaman M, Khudiyev T, Ozgur E, et al. Arrays of indefinitely long uniform nanowires and nanotubes. Nat Mater 2011, 10: 494-501.

[4] Tsivion D, Schvartzman M, Popovitz-Biro R, et al. Guided growth of millimeter-long horizontal nanowires with controlled orientations. Science 2011, 333: 1003-1007. 
[5] Huang JY, Li Z, Chong MW, et al. In situ observation of the electrochemical lithiation of a single $\mathrm{SnO}_{2}$ nanowire electrode. Science 2010, 330: 1515-1520.

[6] Tian BZ, Zheng XL, Kempa T, et al. Coaxial silicon nanowires as solar cells and nanoelectronic power sources. Nature 2007, 449: 885-889.

[7] Gao PX, Ding Y, Mai WJ, et al. Conversion of zinc oxide nanobelts into superlattice-structured nanohelices. Science 2005, 309: 1700-1704.

[8] Ju SY, Facchetti A, Xuan Y, et al. Fabrication of fully transparent nanowire transistors for transparent and flexible electronics. Nat Nanotechnol 2007, 2: 378-384.

[9] Huang Y, Duan XF, Wei QQ, et al. Directed assembly of one-dimensional nanostructures into functional networks. Science 2001, 291: 630-633.

[10] Law M, Goldberger J, Yang P D. Semiconductor nanowires and nanotubes. Ann Rev Mater Res 2004, 34: 83-122.

[11] Limmer SJ, Seraji S, Wu Y, et al. Template-based growth of various oxide nanorods by sol-gel electrophoresis. Adv Funct Mater 2002, 12: 59-64.

[12] Varghese OK, Grimes CA. Metal oxide nanoarchitectures for environmental sensing. J Nanosci Nanotechnol 2003, 3: 277-293.

[13] Kuchibhatla S, Karakoti AS, Bera D, et al. One dimensional nanostructured materials. Prog Mater Sci 2007, 52: 699-913.

[14] Lu XF, Wang C, Wei Y. One-dimensional composite nanomaterials: synthesis by electrospinning and their applications. Small 2009, 5: 2349-2370.

[15] Li Y, Qian F, Xiang J. et al. Nanowire electronic and optoelectronic devices. Mater Today 2006, 9: 18-27.

[16] Lin D, Wu H, Pan W. Photoswitches and memories assembled by electrospinning aluminum-doped zinc oxide single nanowires. Advanced Materials 2007, 19: 3968-3972.

[17] Lieber CM. One-dimensional nanostructures: Chemistry, physics \& applications. Solid State Comm 1998, 107: 607-616.

[18] Xia YN, Yang PD, Sun YG, et al. One-dimensional nanostructures: Synthesis, characterization, and applications. Adv Mater 2003, 15: 353-389.

[19] Chan CK, Peng H, Liu G, et al. High-performance lithium battery anodes using silicon nanowires. Nat
Nanotechnol 2008, 3: 31-35.

[20] Li YG, Tan B, Wu YY. Mesoporous $\mathrm{CO}_{3} \mathrm{O}_{4}$ nanowire arrays for lithium ion batteries with high capacity and rate capability. Nano Lett 2008, 8: 265-270.

[21] Martin CR. Membrane-based synthesis of nanomaterials. Chem Mater 1996, 8: 1739-1746.

[22] Hulteen JC, Martin CR. A general template-based method for the preparation of nanomaterials. $J$ Mater Chem 1997, 7: 1075-1087.

[23] Dresselhaus, MS, Chen G, Tang MY, et al. New directions for low-dimensional thermoelectric materials. Adv Mater 2007, 19: 1043-1053.

[24] McCann JT, Li D, Xia YN. Electrospinning of nanofibers with core-sheath, hollow, or porous structures. J Mater Chem 2005, 15: 735-738.

[25] Sigmund W, Yuh J, Park H, et al. Processing and structure relationships in electrospinning of ceramic fiber systems. J Am Ceram Soc 2006, 89: 395-407.

[26] Ramaseshan R, Sundarrajan S, Jose R, et al. Nanostructured ceramics by electrospinning. J Appl Phys 2007, 102: 111101-111117.

[27] Li D, Xia YN. Electrospinning of nanofibers: Reinventing the wheel? Adv Mater 2004, 16: 1151-1170.

[28] Teo WE, Ramakrishna S. A review on electrospinning design and nanofibre assemblies. Nanotechnol 2006, 17: R89-R106.

[29] Li D, Wang YL, Xia YN. Electrospinning of polymeric and ceramic nanofibers as uniaxially aligned arrays. Nano Lett 2003, 3: 1167-1171.

[30] Li D, McCann JT, Xia YN. Electrospinning: A simple and versatile technique for producing ceramic nanofibers and nanotubes. J Am Ceram Soc 2006, 89: 1861-1869.

[31] Dersch R, Graeser M, Greiner A, et al. Electrospinning of nanofibres: Towards new techniques, functions, and applications. Aust J Chem 2007, 60: 719-728.

[32] Li D, Xia YN. Fabrication of titania nanofibers by electrospinning. Nano Lett 2003, 3: 555-560.

[33] Li D, Wang YL, Xia YN. Electrospinning nanofibers as uniaxially aligned arrays and layer-by-layer stacked films. Adv Mater 2004, 16: 361-366.

[34] Li D, Xia YN. Direct fabrication of composite and ceramic hollow nanofibers by electrospinning. 
Nano Lett 2004, 4: 933-938.

[35] Wu H, Lin D, Pan W. Fabrication, assembly, and electrical characterization of $\mathrm{CuO}$ nanofibers. Appl Phys Lett 2006, 89: 133125.

[36] Wu H, Pan W. Preparation of zinc oxide nanofibers by electrospinning. J Am Ceram Soc 2006, 89: 699-701.

[37] Lin D, Wu H, Zhang R, et al. Preparation and electrical properties of electrospun tin-doped indium oxide nanowires. Nanotechnol 2007, 18: 465301 .

[38] Lin D, Wu H, Zhang R, et al. Preparation of $\mathrm{ZnS}$ nanofibers via electrospinning. J Am Ceram So 2007, 90: 3664-3666.

[39] Lin D, Pan W, Wu H. Morphological control of centimeter long aluminum-doped zinc oxide nanofibers prepared by electrospinning. $J \mathrm{Am}$ Ceram Soc 2007, 90: 71-76.

[40] Lin D, Wu H, Pan W. Preparation of Eu, Li Co-doped $\mathrm{ZnO}$ red fluorescence nanofibers by electrospinning and their characterization. Rare Metal Mater Eng 2007, 36: 220-222.

[41] $\mathrm{Wu} \mathrm{H,} \mathrm{Lin} \mathrm{D,} \mathrm{Zhang} \mathrm{R,} \mathrm{et} \mathrm{al.} \mathrm{Oriented} \mathrm{nanofibers}$ by a newly modified electrospinning method. $\mathrm{J} \mathrm{Am}$ Ceram Soc 2007, 90: 632-634.

[42] Wu H, Zhang R, Liu XX, et al. Electrospinning of $\mathrm{Fe}, \mathrm{Co}$, and Ni nanofibers: Synthesis, assembly, and magnetic properties. Chem Mater 2007, 19: 3506-3511.

[43] $\mathrm{Wu} \mathrm{H,} \mathrm{Lin} \mathrm{D}$, Zhang $\mathrm{R}$, et al. $\mathrm{ZnO}$ nanofiber field-effect transistor assembled by electrospinning. J Am Ceram Soc 2008, 91: 656-659.

[44] Wu H, Zhang R, Sun Y, et al. Biomimetic nanofiber patterns with controlled wettability. Soft Matter 2008, 4: 2429-2433.

[45] Li HP, Wu H, Lin DD, et al. High $T_{\mathrm{c}}$ in electrospun $\mathrm{BaTiO}_{3}$ nanofibers. J Am Ceram Soc 2009, 92: 2162-2164.

[46] Li HP, Wu H, Pan W. Preparation of $\mathrm{BaTiO}_{3}$ nanofibers via electrospinning. Rare Metal Mater Eng 2009, 38: 994-996.

[47] Lin D, Wu H, Zhang R, et al. Enhanced photocatalysis of electrospun Ag- $\mathrm{ZnO}$ heterostructured nanofibers. Chem Mater 2009, 21: 3479-3484.

[48] Lin D, Wu H, Zhang W, et al. Enhanced UV photoresponse from heterostructured $\mathrm{Ag}-\mathrm{ZnO}$ nanowires. Appl Phys Lett 2009, 94: 172103.
[49] Qin XL, Wu H, Lin DD, et al. Preparation of $\mathrm{ZnO}$ nanofibers with high specific surface area. Rare Metal Mater Eng 2009, 38: 997-999.

[50] Wu H, Sun Y, Lin D, et al. GaN nanofibers based on electrospinning: Facile synthesis, controlled assembly, precise doping, and application as high performance UV photodetector. Adv Mater 2009, 21: 227-231.

[51] Zhang $\mathrm{R}$, Wu H, Lin $\mathrm{D}$, et al. Preparation of necklace-structured $\mathrm{TiO}_{2} / \mathrm{SnO}_{2}$ hybrid nanofibers and their photocatalytic activity. J Am Ceram Soc 2009, 92: 2463-2466.

[52] Zhang $\mathrm{R}, \mathrm{Wu} \mathrm{H}$, Lin $\mathrm{D}$, et al. $\mathrm{LaMnO}_{3}$ and $\mathrm{La}_{0.875} \mathrm{Sr}_{0.125} \mathrm{MnO}_{3}$ nanofibers via electrospinning. Rare Metal Mater Eng 2009, 38: 1000-1002.

[53] Li HP, Sun Y, Zhang W, et al. Preparation of heterostructured $\mathrm{Ag} / \mathrm{BaTiO}_{3}$ nanofibers via electrospinning. J Alloys Comp 2010, 508: 536-539.

[54] Li HP, Zhang W, Li B, et al. Diameter-dependent photocatalytic activity of electrospun $\mathrm{TiO}_{2}$ nanofiber. J Am Ceram Soc 2010, 93: 2503-2506.

[55] Zhang R, Wu H, Lin D, et al. Photocatalytic and magnetic properties of the $\mathrm{Fe}-\mathrm{TiO}_{2} / \mathrm{SnO}_{2}$ nanofiber via electrospinning. $J$ Am Ceram Soc 2010, 93: 605-608.

[56] Li HP, Zhang W, Pan W. Enhanced photocatalytic activity of electrospun $\mathrm{TiO}_{2}$ nanofibers with optimal anatase/rutile ratio. J Am Ceram Soc 2011, 94: 3184-3187.

[57] Lin D, Wu H, Zhang R, et al. Facile synthesis of heterostructured $\mathrm{ZnO}-\mathrm{ZnS}$ nanocables and enhanced photocatalytic activity. J Am Ceram Soc 2010, 93: 3384-3389.

[58] Wu H, Lin D, Pan W. High performance surfaceenhanced Raman scattering substrate combining low dimensional and hierarchical nanostructures. Langm 2010, 26: 6865-6868.

[59] Huang ZM, Zhang YZ, Kotaki M, et al. A review on polymer nanofibers by electrospinning and their applications in nanocomposites. Comp Sci Technol 2003, 63: 2223-2253.

[60] Pham QP, Sharma U, Mikos AG. Electrospinning of polymeric nanofibers for tissue engineering applications: A review. Tissue Eng 2006, 12: 1197-1211.

[61] Li D, Herricks T, Xia YN. Magnetic nanofibers of nickel ferrite prepared by electrospinning. Appl 
Phys Lett 2003, 83: 4586-4588.

[62] Kim JK, Chauhan GS, Ahn JH, et al. Effect of synthetic conditions on the electrochemical properties of $\mathrm{LiMn}_{0.4} \mathrm{Fe}_{0.6} \mathrm{PO}_{4} / \mathrm{C}$ synthesized by sol-gel technique. J Power Sources 2009, 189: 391-396.

[63] Lee SH, Jung M, Im JS, et al. Preparation and characterization of electrospun $\mathrm{LiFePO}(4) /$ carbon complex improving rate performance at high C-rate. Res Chem Intermed 2010, 36: 591-602.

[64] Lu HW, Yu L, Zeng W, et al. Fabrication and electrochemical properties of three-dimensional structure of LiCoO fibers. Electrochem Solid State Lett 2008, 11: A140-A144.

[65] Zhan SH, Li Y, Yu HB. $\mathrm{LiCoO}_{2}$ hollow nanofibers by co-electrospinning sol-gel precursor. $J$ Dispersion Sci Technol 2008, 29: 702-705.

[66] Gu YX, Chen DR, Jiao ML. Synthesis and electrochemical properties of nanostructured $\mathrm{LiCoO}_{2}$ fibers as cathode materials for lithium-ion batteries. J Phys Chem B 2005, 109: 17901-17906.

[67] Shao CL, Yu N, Liu YC, Preparation of $\mathrm{LiCoO}_{2}$ nanofibers by electrospinning technique. J Phys Chem Solids 2006, 67: 1423-1426.

[68] Fu ZW, Ma J, Qin QZ. Nanostructured $\mathrm{LiCoO}_{2}$ and $\mathrm{LiMn}_{2} \mathrm{O}_{4}$ fibers fabricated by a high frequency electrospinning. Solid State Ionics 2005, 176: 1635-1640.

[69] Shao CL, Guan HY, Wen SB, et al. A novel method for making $\mathrm{NiO}$ nanofibres via an electrospinning technique. Chin Chem Lett 2004, 15: 365-367.

[70] Moon J, Park JA, Lee SJ, et al. Structure and electrical properties of electrospun $\mathrm{Zno}-\mathrm{NiO}$ mixed oxide nanofibers. Current ApplPhys 2009, 9: S213-S216.

[71] Guan HY, Shao CL, Wen SB, et al. Preparation and characterization of $\mathrm{NiO}$ nanofibres via an electrospinning technique. Inorg Chem Comm 2003, 6: 1302-1303.

[72] Shao CL, Yang XH, Guan HY, et al. Electrospun nanofibers of $\mathrm{NiO} / \mathrm{ZnO}$ composite. Inorg Chem Comm 2004, 7: 625-627.

[73] Fan Q, Whittingham MS. Electrospun manganese oxide nanofibers as anodes for lithium-ion batteries. Electrochem Solid State Lett 2007, 10: A48-A51.

[74] Zhan SH, Chen DR, Jiao XL, et al. Facile fabrication of long $\alpha-\mathrm{Fe}_{2} \mathrm{O}_{3}, \alpha-\mathrm{Fe}$ and $\gamma-\mathrm{Fe}_{2} \mathrm{O}_{3}$ hollow fibers using sol-gel combined co-elecrospinning technology. J Colloid Interf Sci 2007, 308: 265-270.

[75] Zhu Y, Zhang JC, Zhai J, et al. Preparation of superhydrophilic $\alpha-\mathrm{Fe}_{2} \mathrm{O}_{3}$ nanofibers with tunable magnetic properties. Thin Solid Films 2006, 510: 271-274.

[76] Park SJ, Bhargava S, Bender ET, et al. Palladium nanoparticles supported by alumina nanofibers synthesized by electrospinning. J Mate Res 2008, 23: 1193-1196.

[77] Yang XH, Shao CL, Liu YC. Fabrication of $\mathrm{Cr}_{2} \mathrm{O}_{3} /$ $\mathrm{Al}_{2} \mathrm{O}_{3}$ composite nanofibers by electrospinning. $J$ Mater Sci 2007, 42: 8470-8472.

[78] Peng Q, Sun XY, Spagnola JC, et al. Atomic layer deposition on electrospun polymer fibers as a direct route to $\mathrm{Al}_{2} \mathrm{O}_{3}$ microtubes with precise wall thickness control. Nano Lett 2007, 7: 719-722.

[79] Rose M, Kockrick E, Senkovska I, et al. High surface area carbide-derived carbon fibers produced by electrospinning of polycarbosilane precursors. Carbon 2010, 48: 403-407.

[80] Shin DG, Riu DH, Kim HE. Web-type silicon carbide fibers prepared by the electrospinning of polycarbosilanes. J Ceram Process Res 2008, 9: 209-214.

[81] Kim SJ, Yun SM, Lee YS. Characterization of nanocrystalline porous $\mathrm{SiC}$ powder by electrospinning and carbothermal reduction. J Indus Eng Chem 2010, 16: 273-277.

[82] Eick B, Youngblood J. SiC nanofibers by pyrolysis of electrospun preceramic polymers. J Mater Sci 2009, 44: 160-165.

[83] Qiu YJ, Yu J, Rafique J, et al. Large-scale production of aligned long boron nitride nanofibers by multijet/multicollector electrospinning. J Phys Chem C 2009, 113: 11228-11234.

[84] Cui XM, Nam YS, Lee JY, et al. Fabrication of zirconium carbide ( $\mathrm{ZrC})$ ultra-thin fibers by electrospinning. Mater Lett 2008, 62: 1961-1964.

[85] Zhu PW, Hong YL, Liu BB, et al. The synthesis of titanium carbide-reinforced carbon nanofibers. Nanotechnol 2009, 20: 255603.

[86] Kang PH, Jeun JP, Seo DK, et al. Fabrication of SiC mat by radiation processing. Radia Phys Chem 2009, 78: 493-495.

[87] Zhang SH, Xu SZ, Dong XT, et al. New research progress on coaxial nanocables. Rare Metal Mater 
Eng 2008, 37: 1117-1123.

[88] Li D, Babel A, Jenekhe SA, et al. Nanofibers of conjugated polymers prepared by electrospinning with a two-capillary spinneret. Adv Mater 2004, 16: 2062-2066.

[89] Xiang J, Chu YQ, Zhou GZ, et al. Electrospinning preparation, structural and magnetic properties of $\mathrm{Li}_{0.5-0.5 x} \mathrm{Zn}_{x} \mathrm{Fe}_{2.5-0.5 x} \mathrm{O}_{4}$ nanofibers. Acta Chim Sinica 2011, 69: 2457-2464.

[90] Nam JH, Joo YH, Lee JH, et al. Preparation of NiZn-ferrite nanofibers by electrospinning for DNA separation. J Magnetism Magnetic Mater 2009, 321: 1389-1392.

[91] Wang ZL, Liu XJ, Lv MF, et al. Preparation of one-dimensional $\mathrm{CoFe}_{2} \mathrm{O}_{4}$ nanostructures and their magnetic properties. J Phys Chem C 2008, 112: 15171-15175.

[92] Liu MQ, Shen XQ, Song FZ, et al. Microstructure and magnetic properties of electrospun onedimensional $\mathrm{Al}^{3+}$-substituted $\mathrm{SrFe}_{12} \mathrm{O}_{19}$ nanofibers. J Solid State Chem 2011, 184: 871-876.

[93] Zheng W, :I ZY, Zhang HN, et al. Electrospinning route for $\alpha-\mathrm{Fe}_{2} \mathrm{O}_{3}$ ceramic nanofibers and their gas sensing properties. Mater Res Bull 2009, 44: 1432-1436.

[94] Cai ZY, Song J, Li JS, et al. Synthesis of $\mathrm{LiNi}_{1 / 3} \mathrm{Co}_{1 / 3} \mathrm{Mn}_{1 / 3} \mathrm{O}_{2}$ nanoparticles by modified Pechini method and their enhanced rate capability. $J$ Sol-Gel Sci Technol 2012, 61: 49-55.

[95] Guo BK, Li Y, Yao YF, et al. Electrospun $\mathrm{Li}_{4} \mathrm{Ti}_{5} \mathrm{O}_{12} / \mathrm{C}$ composites for lithium-ion batteries with high rate performance. Solid State Ionics 2011, 204: 61-65.

[96] Ji LW, Lin Z, Alcouttabi M, et al. Electrospun carbon nanofibers decorated with various amounts of electrochemically-inert nickel nanoparticles for use as high-performance energy storage materials. Rsc Adv 2012, 2: 192-198.

[97] Kong JH, Liu ZL, Yang ZC, et al. Carbon/ $\mathrm{SnO}_{2} /$ carbon core/shell/shell hybrid nanofibers: tailored nanostructure for the anode of lithium ion batteries with high reversibility and rate capacity. Nanoscale 2012, 4: 525-530.

[98] Lee BS, Son SB, Park KM, et al. Anodic properties of hollow carbon nanofibers for Li-ion battery. $J$ Power Sources 2012, 199: 53-60.

[99] Wang HY, Gao P, Lu SF, et al. The effect of tin content to the morphology of Sn/carbon nanofiber and the electrochemical performance as anode material for lithium batteries. Electrochim Acta 2011, 58: 44-51.

[100]Zhu PN, Wu YZ, Reddy MV, et al. Long term cycling studies of electrospun $\mathrm{TiO}_{2}$ nanostructures and their composites with MWCNTs for rechargeable Li-ion batteries. $R s c A d v$ 2012, 2: 531-537.

[101] Alcoutlabi M, Ji LW, Guo BK, et al. Electrospun nanofibers for energy storage. Aatcc Review 2011, 11: 45-51.

[102] Cavaliere S, Subianto S, Savych I, et al. Electrospinning: Designed architectures for energy conversion and storage devices. Energy Environ Sci 2011, 4: 4761-4785.

[103] Han H, Song T, Bae JY, et al. Nitridated $\mathrm{TiO}_{2}$ hollow nanofibers as an anode material for high power lithium ion batteries. Energy Environ Sci 2011, 4: 4532-4536.

[104] Ji LW, Rao MM, Aloni S, et al. Porous carbon nanofiber-sulfur composite electrodes for lithium/ sulfur cells. Energy Environ Sci 2011, 4: 5053-5059.

[105] Jung HR, Lee WJ. Electrochemical characterization of electrospun $\mathrm{SnO}(x)$-embedded carbon nanofibers anode for lithium ion battery with EXAFS analysis. J Electroanaly Chem 2011, 662: 334-342.

[106] Zhao G, Liu SW, Lu QF, et al. Preparation of $\mathrm{Bi}_{2} \mathrm{WO}_{6}$ by electrospinning: researching their synthesis mechanism and photocatalytic activity. $J$ Cluster Sci 2011, 22: 621-631.

[107] Choi HS, Kim T, Im JH, et al. Preparation and electrochemical performance of hyper-networked $\mathrm{Li}_{4} \mathrm{Ti}_{5} \mathrm{O}_{12} /$ carbon hybrid nanofiber sheets for a battery-supercapacitor hybrid system. Nanotechnol. 2011, 22: 405402

[108] Doan TQ, Boyle TJ, Ottley LAM, et al. Synthesis, characterization, electrospinning of novel tin amide alkoxides for lithium-ion battery application. In: 241st ACS National Meeting\&Exposition. Anaheim, USA, 2011.

[109] Lee JS, Kwon OS, Park SJ, et al. Fabrication of ultrafine metal-oxide-decorated carbon nanofibers for DMMP sensor application. Acs Nano 2011, 5: $7992-8001$.

[110] Roginskaya YE, Sheppelve AD, Tenchurin TK, et al. 
Synthesis and structure of composite fibers based on silicon and carbon obtained by electrospinning. Russ J Phys Chem A 2011, 85: 2013-2019.

[111] Toprakci O, Ji LW, Lin Z, et al. Fabrication and electrochemical characteristics of electrospun $\mathrm{LiFePO}_{4} /$ carbon composite fibers for lithium-ion batteries. J Power Sources 2011, 196: 7692-7699.

[112] Yang XJ, Teng DH, Liu BX, et al. Nanosized anatase titanium dioxide loaded porous carbon nanofiber webs as anode materials for lithium-ion batteries. Electrochem Comm 2011, 13: 1098-1101.

[113] Zhang P, Guo ZP, Huang YD, et al. Synthesis of $\mathrm{Co}_{3} \mathrm{O}_{4} /$ carbon composite nanowires and their electrochemical properties. J Power Sources 2011, 196: 6987-6991.

[114] Bonino CA, Ji LW, Lin Z, et al. Electrospun carbon-tin oxide composite nanofibers for use as lithium ion battery anodes. Acs Appl Mater Interf 2011, 3: 2534-2542.

[115] Chang DR, Heo GS. Fabrication and electrochemical characterization of carbon nanofibers by electrospinning with various $\mathrm{MnO}_{2}$ contents. E-Polymers, 2011, 075.

[116] Cheah YL, Gupta N, Pramana SS, et al. Morphology, structure and electrochemical properties of single phase electrospun vanadium pentoxide nanofibers for lithium ion batteries. $J$ Power Sources 2011, 196: 6465-6472.

[117] Chen LJ, Liao JD, Chuang YJ, et al. Synthesis and characterization of $\mathrm{PVP} / \mathrm{LiCoO}_{2}$ nanofibers by electrospinning route. J Appl Polym Sci 2011, 121: 154-160.

[118] Dong ZX, Kennedy SJ, Wu YQ. Electrospinning materials for energy-related applications and devices. J Power Sources 2011, 196: 4886-4904.

[119] Jung HR, Cho SJ, Kim KN, et al. Electrochemical properties of electrospun $\mathrm{Cu}_{x} \mathrm{O}(x=1,2)$-embedded carbon nanofiber with EXAFS analysis. Electrochim Acta 2011, 56: 6722-6731.

[120] Wang L, We Lj, Li ZH, et al. Synthesis and electrochemical properties of $\mathrm{Li}_{2} \mathrm{ZnTi}_{3} \mathrm{O}_{8}$ fibers as an anode material for lithium-ion batteries. Electrochim Acta 2011, 56: 5343-5346.

[121] Croce F, Focarete ML, Hassoun J, et al. A safe, high-rate and high-energy polymer lithium-ion battery based on gelled membranes prepared by electrospinning. Energy Environ Sci 2011, 4:
921-927.

[122] Dai YQ, Liu WY, Formo E, et al. Ceramic nanofibers fabricated by electrospinning and their applications in catalysis, environmental science, and energy technology. Polym Adv Technol 2011, 22: 326-338.

[123] Kong JH, Wong SY, Zhang Y, et al. Onedimensional carbon- $\mathrm{SnO}_{2}$ and $\mathrm{SnO}_{2}$ nanostructures via single-spinneret electrospinning: Tunable morphology and the underlying mechanism. J Mater Chem 2011, 21: 15928-15934.

[124] Lijo F, Marsano E, Vijila C, et al. Electrospun polyimide/titanium dioxide composite nanofibrous membrane by electrospinning and electrospraying. $J$ Nanosci Nanotechnol 2011, 11: 1154-1159.

[125] Mu JB, Chen B, Guo ZC, et al. Tin oxide $\left(\mathrm{SnO}_{2}\right)$ nanoparticles/electrospun carbon nanofibers (CNFs) heterostructures: controlled fabrication and high capacitive behavior. J Colloid Interf Sci 2011, 356: 706-712.

[126] Hwang DK, Kim S, Lee JH, et al. Phase evolution of perovskite $\mathrm{LaNiO}_{3}$ nanofibers for supercapacitor application and p-type gas sensing properties of LaOCl-NiO composite nanofibers. $J$ Mater Chem 2011, 21: 1959-1965.

[127] Yuan T, Zhao BT, Cai R, et al. Electrospinning based fabrication and performance improvement of film electrodes for lithium-ion batteries composed of $\mathrm{TiO}_{2}$ hollow fibers. $J$ Mater Chem 2011, 21 : 15041-15048.

[128] Zhang XW, Ji LW, Toprakci O, et al. Electrospun nanofiber-based anodes, cathodes, and separators for advanced lithium-ion batteries. Polym Rev 2011, 51: 239-264.

[129] Zhu CB, Yu Y, Gu L, et al. Electrospinning of highly electroactive carbon-coated single-crystalline $\mathrm{LiFePO}_{4}$ nanowires. Angewandte Chemie Inter Ed 2011, 50: 6278-6282.

[130] Jung HR, Lee WJ. Preparation and characterization of Ni-Sn/carbon nanofibers composite anode for lithium ion battery. J Electrochem Soc 2011, 158: A644-A652.

[131] Laudenslager MJ, Scheffler RH, Sigmund WM. Electrospun materials for energy harvesting, conversion, and storage: A review. Pure Appl Chem 2010, 82: 2137-2156.

[132] Luo W, Hu XL, Sun YM, et al. Electrospinning of 
carbon-coated $\mathrm{MoO}_{2}$ nanofibers with enhanced lithium-storage properties. Phys Chem Chem Phys 2011, 13: 16735-16740.

[133] Mai LQ, Xu L, Han CH, et al. Electrospun ultralong hierarchical vanadium oxide nanowires with high performance for lithium ion batteries. Nano Lett 2010, 10: 4750-4755.

[134] Barth S, Hernandez-Ramirez F, Holmes JD, et al. Synthesis and applications of one-dimensional semiconductors. Prog Mater Sci 2010, 55: 563-627.

[135] Lee YS, Jeong YB, Kim DW. Cycling performance of lithium-ion batteries assembled with a hybrid composite membrane prepared by an electrospinning method. J Power Sources 2010, 195: 6197-6201.

[136] Li LM, Yin XM, Liu S, et al. Electrospun porous $\mathrm{SnO}_{2}$ nanotubes as high capacity anode materials for lithium ion batteries. Electrochem Comm 2010, 12: $1383-1386$.

[137] Miao JJ, Miyauchi M, Simmons TJ, et al. Electrospinning of nanomaterials and applications in electronic components and devices. J Nanosci Nanotechnol 2010, 10: 5507-5519.

[138] Yang ZX, Du GD, Guo ZP, et al. Easy preparation of $\mathrm{SnO}_{2} @$ carbon composite nanofibers with improved lithium ion storage properties. $J$ Mater Res 2010, 25: 1516-1524.

[139] Liu HQ, Yang JX, Liang JH, et al. ZnO nanofiber and nanoparticle synthesized through electrospinning and their photocatalytic activity under visible light. J Am Ceram Soc 2008, 91: 1287-1291.

[140] Neubert S, Pliszka D, Thavasi V, et al. Conductive electrospun PANi-PEO/TiO 2 fibrous membrane for photo catalysis. Mater Sci Eng B 2011, 176: 640-646.

[141] Reddy KR, Nakata K, Ochiai T, et al. Nanofibrous $\mathrm{TiO}_{2}$-core/conjugated polymer-sheath composites: synthesis, structural properties and photocatalytic activity. J Nanosci Nanotechnol 2010, 10: 7951-7957.

[142] Yi C, Nirmala R, Navamathavan R, et al. Preparation of photocrosslinkable polystyrene methylene cinnamate nanofibers via electrospinning. J Nanosci Nanotechnol 2011, 11: 8474-8480.

[143] Huang JS, Wang DW, Hou HQ, et al. Electrospun palladium nanoparticle-loaded carbon nanofibers and their electrocatalytic activities towards hydrogen peroxide and NADH. Adv Funct Mater 2008, 18: 441-448.

[144] Ostermann R, Li D, Yin YD, et al. $\mathrm{V}_{2} \mathrm{O}_{5}$ nanorods on $\mathrm{TiO}_{2}$ nanofibers: a new class of hierarchical nanostructures enabled by electrospinning and calcination. Nano Lett 2006, 6: 1297-1302.

[145] Cao TP, Li YJ, Wang CH, et al. A facile in situ hydrothermal method to $\mathrm{SrTiO}_{3} / \mathrm{TiO}_{2}$ nanofiber heterostructures with high photocatalytic activity. Langmuir 2011, 27: 2946-2952.

[146] Li CJ, Wang JN, Li XY, et al. Functionalization of electrospun magnetically separable $\mathrm{TiO}_{2}$-coated $\mathrm{SrFe}_{12} \mathrm{O}_{19}$ nanofibers: strongly effective photocatalyst and magnetic separation. J Mater Sci 2011, 46: 2058-2063.

[147] Li XY, Wang, FF, Qian QR, et al. $\mathrm{Ag} / \mathrm{TiO}_{2}$ nanofibers heterostructure with enhanced photocatalytic activity for parathion. Mater Lett 2012, 66: 370-373.

[148] Ochanda FO, Barnett MR. Synthesis and characterization of silver nanoparticles and titanium oxide nanofibers: toward multifibrous nanocomposites. J Am Ceram Soc 2010, 93: 2637-2643.

[149] Su CY, Shao CL, Liu YC. Electrospun nanofibers of $\mathrm{TiO}_{2} / \mathrm{CdS}$ heteroarchitectures with enhanced photocatalytic activity by visible light. $J$ Colloid Interf Sci 2011, 359: 220-227.

[150] Wang CH, Zhang XT, Shao CL, et al. Rutile $\mathrm{TiO}_{2}$ nanowires on anatase $\mathrm{TiO}_{2}$ nanofibers: A branched heterostructured photocatalysts via interfaceassisted fabrication approach. J Colloid Interf Sci 2011, 363: 157-164.

[151] Zhang P, Shao CL, Zhang ZY, et al. Core/shell nanofibers of $\mathrm{TiO}_{2} @$ carbon embedded by $\mathrm{Ag}$ nanoparticles with enhanced visible photocatalytic activity. J Mater Chem 2011, 21: 17746-17753.

[152] Zhang ZY, Shao CL, Li XT, et al. Electrospun nanofibers of p-type $\mathrm{NiO} / \mathrm{n}$-type $\mathrm{ZnO}$ heterojunctions with enhanced photocatalytic activity. Acs Appl Mater Interf 2011, 2: 2915-2923.

[153] Choi SK, Kim S, Lim SK, et al. Highly enhanced photocatalytic activities of electrospun mesoporous $\mathrm{TiO}_{2}$ nanofiber. Abst Papers Am Chem Soc 2010, 239.

[154] Lee JA, Nam YS, Rutledge GC, et al. Enhanced photocatalytic activity using layer-by-layer electrospun constructs for water remediation. Adv Funct 
Mater 2010, 20: 2424-2429.

[155] Zhang TZ, Ge LQ, Wang X, et al. Hollow $\mathrm{TiO}_{2}$ containing multilayer nanofibers with enhanced photocatalytic activity. Polymer 2008, 49: 2898-2902.

[156] Ke XB, Ribbens S, Fan YQ, et al. Integrating efficient filtration and visible-light photocatalysis by loading Ag-doped zeolite Y particles on filtration membrane of alumina nanofibers. J Membrane Sci 2011, 375: 69-74.
[157] Ke XB, Zheng ZF, Liu HW, et al. High-flux ceramic membranes with a nanomesh of metal oxide nanofibers. J Phys Chem B 2008, 112: 5000-5006.

[158] Zhao YF, Sugiyama S, Miller $\mathrm{T}$, et al. Nanoceramics for blood-borne virus removal. Expert Rev Medical Devices 2008, 5: 395-405.

[159] Cao YH, Wu H, Hu LB, et al. Electrospun $\mathrm{SiO}_{2 \mathrm{n}}$ nanofiber as a battery separator. Abst Papers Am Chem Soc 2011, 241. 